\title{
Damaged Spent Nuclear Fuel at U.S. DOE Facilities, Experience and Lessons Learned
}

\author{
Brett Carlsen
}

Denzel Fillmore

Roger McCormack

Robert Sindelar

Timothy Spieker

Eric Woolstenhulme

November 2005

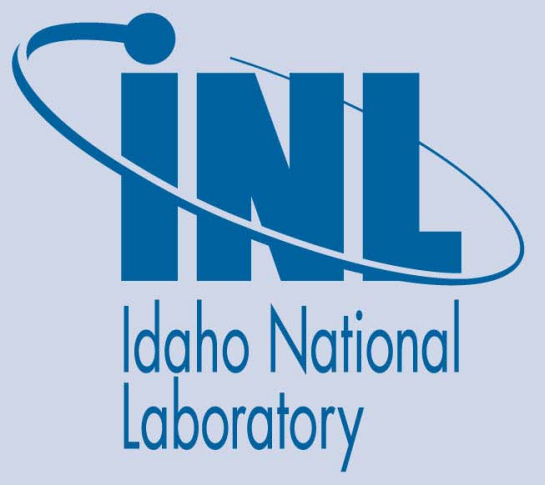

The INL is a U.S. Department of Energy National Laboratory operated by Battelle Energy Alliance 
INL/EXT-05-00760

\title{
Damaged Spent Nuclear Fuel at U.S. DOE Facilities, Experience and Lessons Learned
}

\author{
Brett Carlsen \\ Denzel Fillmore \\ Roger McCormack \\ Robert Sindelar \\ Timothy Spieker \\ Eric Woolstenhulme
}

November 2005

\begin{abstract}
Idaho National Laboratory
Idaho Falls, Idaho 83415
\end{abstract}

Prepared for the

U.S. Department of Energy

Assistant Secretary for Environmental Management

Under DOE Idaho Operations Office

Contract DE-AC07-05ID14517 


\title{
Damaged Spent Nuclear Fuel at U.S. DOE Facilities, Experience and Lessons Learned
}

\author{
INL/EXT-05-00760
}

November 2005

Approved by

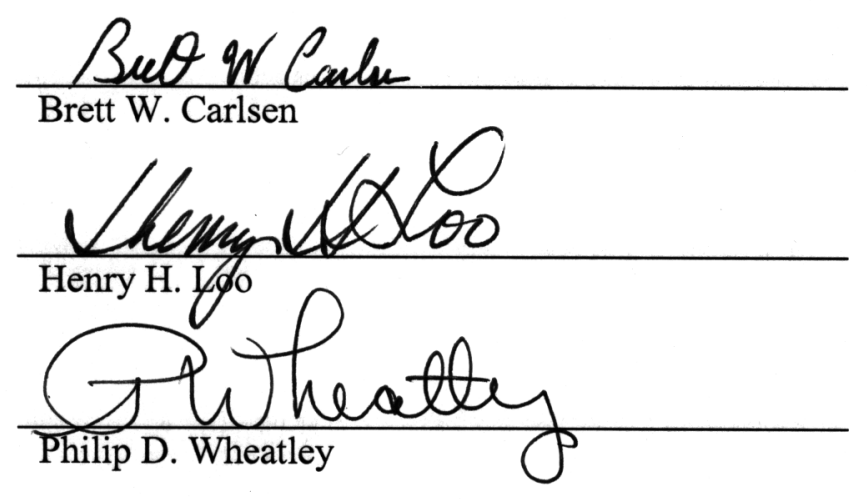

$11 / 30 / 2005$
$\frac{11 / 30 / 2005}{\text { Date }}$
$\frac{11.30 .05}{\text { Date }}$





\begin{abstract}
From a handling perspective, any spent nuclear fuel (SNF) that has lost its original technical and functional design capabilities with regard to handling and confinement can be considered as damaged. Some SNF was damaged as a result of experimental activities and destructive examinations; incidents during packaging, handling, and transportation; or degradation that has occurred during storage. Some SNF was mechanically destroyed to protect proprietary SNF designs. Examples of damage to the SNF include failed cladding, failed fuel meat, sectioned test specimens, partially reprocessed SNFs, over-heated elements, dismantled assemblies, and assemblies with lifting fixtures removed. In spite of the challenges involved with handling and storage of damaged SNF, the SNF has been safely handled and stored for many years at DOE storage facilities. This report summarizes a variety of challenges encountered at DOE facilities during interim storage and handling operations along with strategies and solutions that are planned or were implemented to ameliorate those challenges. A discussion of proposed paths forward for moving damaged and nondamaged SNF from interim storage to final disposition in the geologic repository is also presented.
\end{abstract}




\section{SUMMARY}

The U.S. Department of Energy (DOE) is responsible for storage and final disposition of spent nuclear fuel (SNF) that spans several decades of nuclear research and defense-related material production. To support nuclear nonproliferation objectives, DOE is retrieving many foreign research reactor fuels. These DOE fuels, which have been stored at many different foreign and domestic sites in various configurations and under a variety of conditions, are being consolidated for interim storage at the Idaho National Laboratory (INL), the Hanford Site, and the Savannah River Site.

SNF in DOE custody consists of several hundred different SNF types. These SNFs come from a wide range of reactor types with various SNF compounds, cladding materials, and enrichments. Some of these SNFs are damaged as a result of experimental activities and destructive examinations; incidents during packaging, handling, and transportation; or degradation that has occurred during storage. In spite of the challenges involved with damaged SNFs, these SNFs have been safely handled and stored for many years at DOE storage facilities.

This report summarizes some of the challenges encountered and solutions implemented to ensure safe storage and handling of damaged SNFs. It includes a brief summary of some SNF storage environments and resulting SNF degradation, experience handling and repackaging significantly degraded SNFs, and the associated lessons learned.

Final disposition of these SNFs will require additional handling and, in some cases, additional repackaging and characterization. This report provides a brief overview of strategies being implemented to minimize the costs and radiological exposure associated with additional analyses, characterization, and repackaging that may be needed to qualify these SNFs for emplacement in a geologic repository. 


\section{CONTENTS}

ABSTRACT

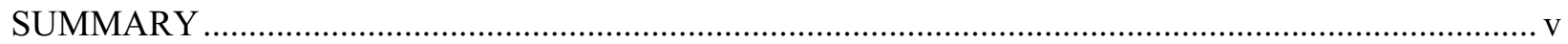

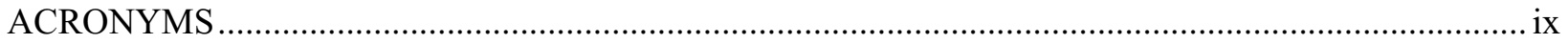

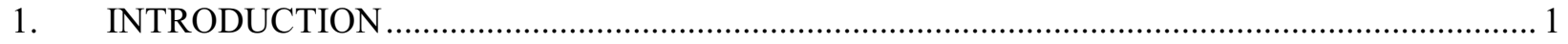

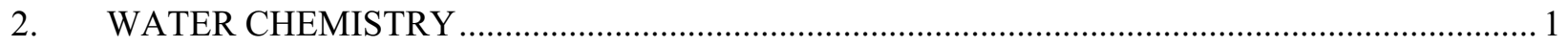

2.1 Water Chemistry-Related Degradation .................................................................... 2

2.2 Estimating Water Quality Impacts from Storage of Damaged SNF................................ 3

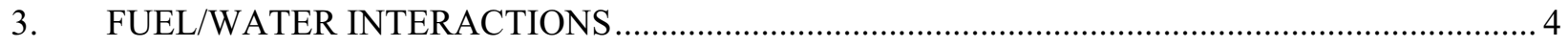

3.1 Spent Nuclear Fuel-Specific Experience ................................................................... 4

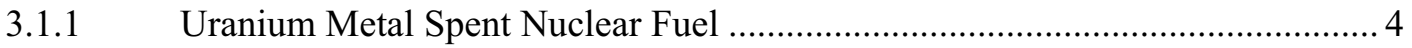

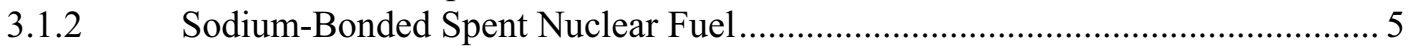

3.1.3 Uranium Carbide Spent Nuclear Fuel .......................................................... 5

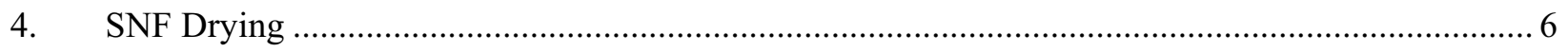

4.1.1 Need for Drying Standards and Supporting Data........................................ 6

4.1.2 Repackaging Considerations and Strategies.................................................... 7

5. OXIDATION OF URANIUM DIOXIDE SPENT NUCLEAR FUEL ….................................. 8

5.1 Factors Affecting Uranium Dioxide Oxidation ........................................................ 8

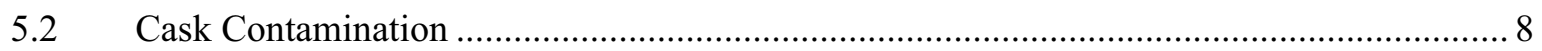

5.3 Uranium Dioxide Oxidation Control Measures............................................................... 9

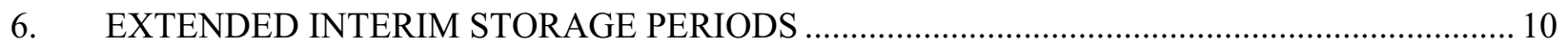

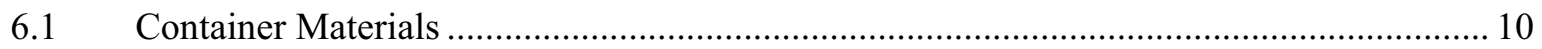

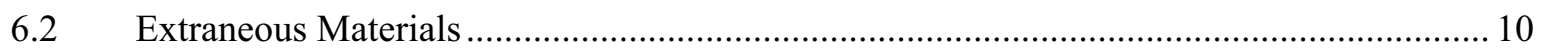

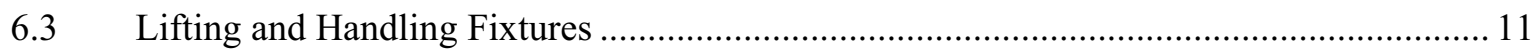

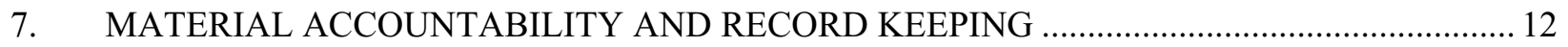

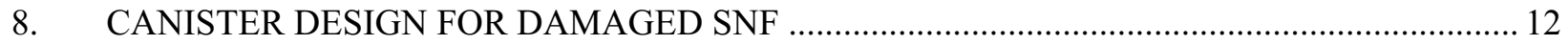

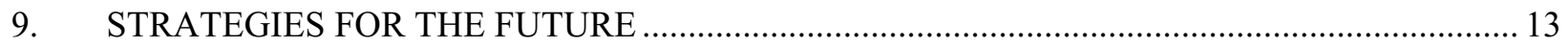

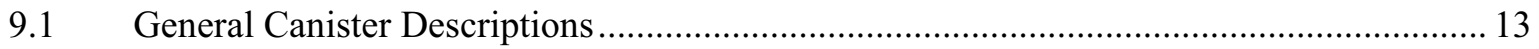




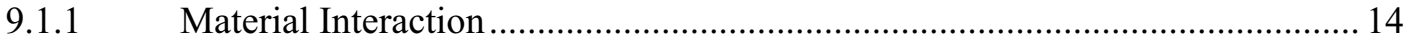

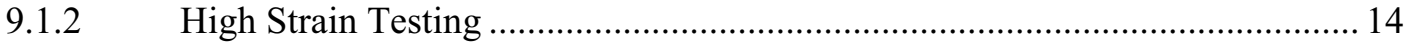

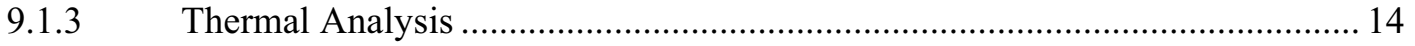

9.2 Advanced Neutron Absorber Development .................................................................. 14

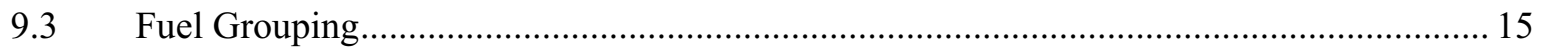

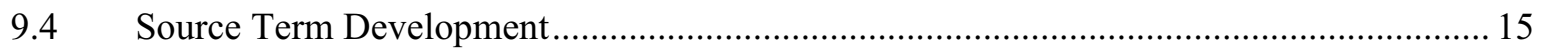

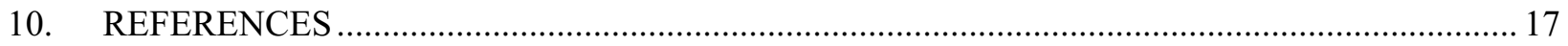

Appendix A—NAC-1E Event Chronology ...............................................................................

Appendix B - Tory IIA Fuel and Packaging Description ............................................................. B-1

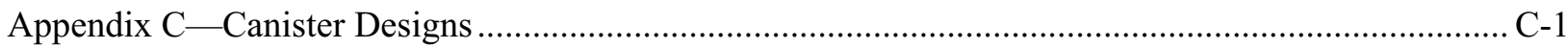

\section{FIGURES}

1. Materials Testing Reactor type assembly with pit corrosion damage on fuel plate cladding

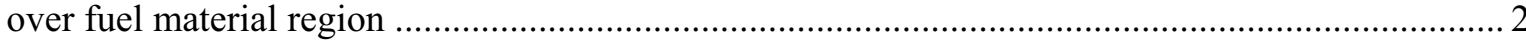

2. Materials Test Reactor type assembly with side plate damage .................................................. 3

3. Examples of uranium metal fuel damage ............................................................................. 5

4. Examples of cladding damage for experiments at Pacific Northwest National Laboratory.............. 9 


\section{ACRONYMS}

DOE U.S. Department of Energy

INL Idaho National Laboratory

MCO multi-canister overpack

NAC Nuclear Assurance Company

SRS Savannah River Site

SNF spent nuclear fuel 


\section{Damaged Spent Nuclear Fuel at U.S. DOE Facilities, Experience and Lessons Learned}

\section{INTRODUCTION}

The U.S. Department of Energy (DOE) is responsible for storage and final disposition of spent nuclear fuel (SNF) that spans several decades of nuclear research and defense-related material production. To support nuclear nonproliferation objectives, DOE is retrieving many foreign research reactor SNFs. These DOE SNFs, which have been stored at many different foreign and domestic sites in various configurations and under a variety of conditions, are being consolidated for interim storage at three major sites across the United States, namely, the Idaho National Laboratory (INL), the Hanford Site, and the Savannah River Site (SRS). SNF in DOE custody consists of several hundred different fuel types. These SNFs come from a wide range of reactor types, such as light and heavy water moderated reactors, graphite-moderated reactors, breeder reactors, with various fuel compounds, cladding materials, and enrichments.

From a handling perspective, any SNF that has lost its original technical and functional design capabilities with regard to handling and/or confinement can be considered as damaged. Some of this SNF was damaged as a result of experimental activities and destructive examinations; inadvertently damaged in the reactor, or from incidents during packaging, handling, and transportation; or degradation that has occurred during storage. Some SNF was mechanically destroyed to protect proprietary SNF designs. Examples of damage to the SNF include failed cladding, failed fuel meat, sectioned test specimens, partially reprocessed SNFs, over-heated elements, dismantled assemblies, and assemblies with lifting fixtures removed. In spite of the challenges involved with handling and storage of damaged SNF, the SNF has been safely handled and stored for many years at DOE storage facilities.

This report summarizes a variety of challenges encountered at DOE facilities during interim storage and handling operations. This report also discusses strategies and solutions that are planned or were implemented to ameliorate those challenges. A discussion of proposed paths forward for moving damaged and nondamaged SNF from interim storage to final disposition in the geologic repository is also presented.

\section{WATER CHEMISTRY}

SNF has historically been stored underwater to provide sufficient decay prior to SNF reprocessing or dry storage. The water provides heat removal, radiological shielding for personnel working in the facility, and confinement of certain fission products. Underwater storage exposes SNF and packaging to the potential for galvanic corrosion. The potential also exists for contamination or corrosion from other materials within the pool, such as chlorine. The presence of chlorides, in particular, can contribute to packaging and fuel corrosion. Within the past, chlorine was sometimes added as a biocide. Degradation of uncoated concrete basins that store the SNF can also contribute to contamination of the basin water with chlorides and metal ions that can corrode metal cladding and structural materials. Stainless steel is a good material for most interim storage but not, as expected, for a high chloride environment. If proper water chemistry is maintained, the stainless steel provides a robust storage design.

Water chemistry is typically controlled to mitigate fuel corrosion. Basin storage systems include stainless steel liners (with leak detection) and filter and deionization systems to maintain basin chemistry and to provide radioactivity removal from the water. Historically, water basin chemistry often has not been as tightly controlled as required to maintain a noncorrosive environment for extended SNF storage. 
Degraded water quality and extended storage periods permit container and SNF degradation, which may lead to breach of containment and release of the radionuclides, and compromise the ability to handle the containers.

\subsection{Water Chemistry-Related Degradation}

Aluminum-based fuel is typically clad with low alloy aluminum. Aluminum alloy cladding and storage system materials are particularly subject to corrosion damage during storage in water basins that have an aggressive water chemistry. Consequently, aluminum is a material to be used with care both as a canister material and as a structural material for holding canisters in a water basin. Various corrosion modes that can lead to cladding penetration within a year of exposure to aggressive water chemistries include pitting, crevice, and galvanic corrosion. Microbiologically influenced corrosion has also been reported to attack aluminum cladding materials in basin storage.

During the early INL basin storage of SNAP SNF in aluminum containers, basin water chemical interactions resulted in the metal of the cans corroding. The corrosion eventually became severe enough that the SNF fell through some of the storage cans to the basin bottom. In this case, the SNF was recovered, without incident, and repackaged in stainless steel cans for ongoing storage where it currently remains.

Figures 1 and 2 are photographs of advanced localized corrosion damage to aluminum-based fuel. If aluminum is to be used in a water storage environment, control of water chemistry is essential. Reference 1 provides a guide describing water chemistry conditions to avoid corrosion damage to aluminum-clad fuel.

Deposits of aluminum hydroxide films on zircaloy clad SNF have also been observed after extended water basin storage in aluminum canisters. Radiolysis of water associated with these films can cause storage container pressurization, weld embrittlement, and flammable gas generation.

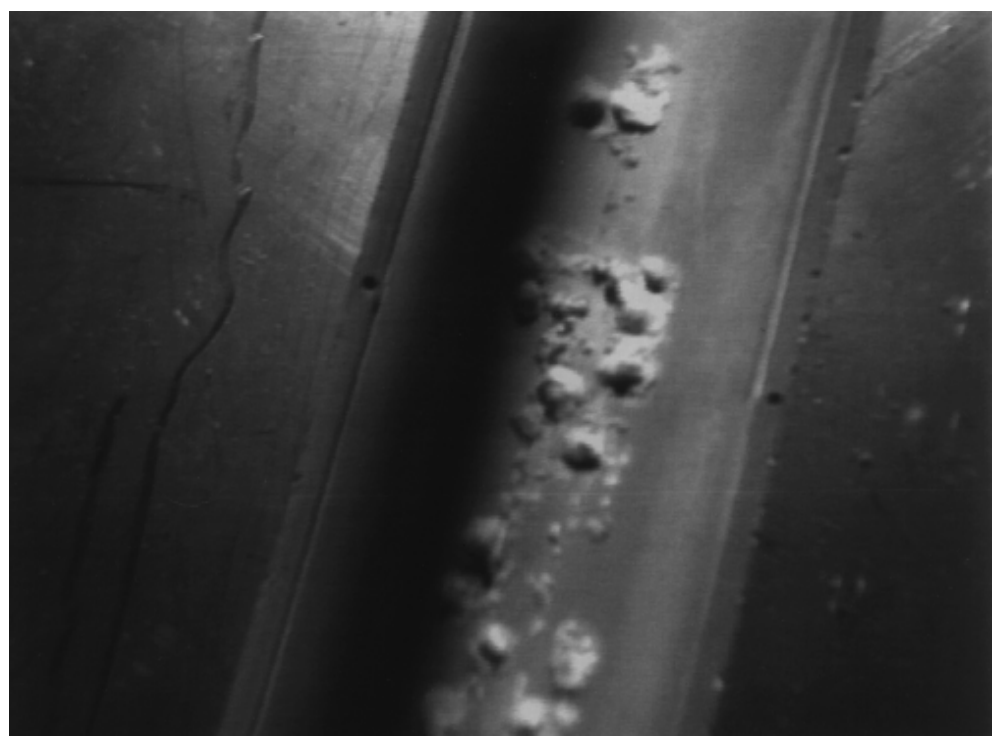

Figure 1. Materials Testing Reactor type assembly with pit corrosion damage on fuel plate cladding over fuel material region. 


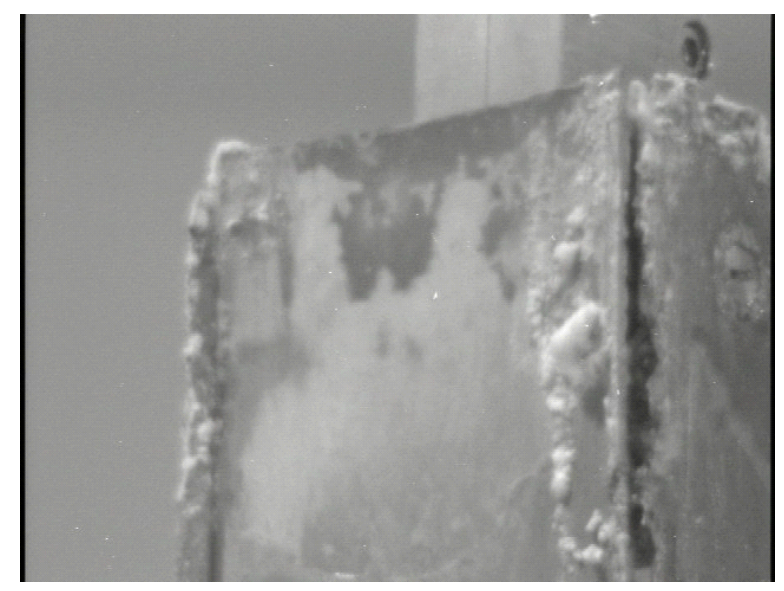

Figure 2. Materials Test Reactor type assembly with side plate damage.

Such issues are controlled through proper water chemistry, which is facilitated by updated basin water control systems. In general, water chemistry issues within DOE facilities are associated with older storage facilities. Water chemistry specifications typically define $\mathrm{pH}$, chloride concentration, conductivity, and basin water temperature. These parameters should be defined in the region that does not accelerate corrosion of materials. Water quality standards for current generation INL facilities limit chlorides to less than $1 \mathrm{ppm}$ and conductivity to less than 2 microsiemens $/ \mathrm{cm}$. Conductivity provides an indirect measure of $\mathrm{pH}$. Consequently, if conductivity is carefully controlled, addition controls on the $\mathrm{pH}$ levels are not necessary. Basin water temperatures are allowed to fluctuate between $\sim 55$ and $85^{\circ} \mathrm{F}$. The fluctuating basin temperatures help make the water less hospitable to biological growth.

\subsection{Estimating Water Quality Impacts from Storage of Damaged SNF}

Exposure of damaged SNF to water in any storage configuration can have deleterious effects. Damaged SNF may have compromised cladding, fuel assembly structural materials, or both. Thus the ability of the fuel assembly to maintain confinement of the fission products is compromised. This may be an issue for continued storage and handling of the fuel in water basins because radionuclides can be released from the fuel causing contamination issues and operations exposure hazards. However, continued storage without placement of SNF in canisters may be feasible for some SNF with breached cladding. A simple methodology can be implemented to estimate the degree of water contamination that results from placement of uncanistered damaged SNF into a basin.

At the low temperatures typical of basin storage (approximately room temperature), corrosion is the primary mechanism whereby species from the fuel core are released into the water. That is, diffusion transport of species from regions in the fuel core to the exposed fuel surface and direct release are not significant. The predominant species affecting basin activity is the ${ }^{137} \mathrm{Cs}$. Gaseous and volatile species, such as krypton and xenon, are minor sources of radioactivity from breached fuel that are released from the basin system and are not significant to operations. Therefore, the estimation of radioactivity release rates from aluminum-based fuel into the basin water focuses on the release rate of ${ }^{137} \mathrm{Cs}$. The ${ }^{137} \mathrm{Cs}$ is assumed to be fully soluble and free to disperse into the basin water and is not bound in the corrosion product. A simple model to estimate the release from fuel core is given by:

$\mathrm{R}_{\mathrm{DF}}=\mathrm{A}_{\mathrm{F}} \times \mathrm{B} \times \mathrm{C}$

where 
$\mathrm{R}_{\mathrm{DF}} \quad$ is the ${ }^{137} \mathrm{Cs}$ release rate $[\mathrm{Ci} / \mathrm{hr}]$ from the damaged fuel

$\mathrm{A}_{\mathrm{F}} \quad$ is the ${ }^{137} \mathrm{Cs}$ activity density in the fuel meat material at the decay time of interest $\left[\mathrm{Ci} / \mathrm{cm}^{3}\right]$

B is the area of fuel exposed to the environment (area of breach) $\left[\mathrm{cm}^{2}\right]$

C is the general corrosion rate of the fuel core material in the environment of exposure $[\mathrm{cm} / \mathrm{hr}]$.

Basin water radioactivity can be controlled through removal of the activity via a resin deionizer. The activity concentration of the basin is directly related to the flow rate through the deionizer and the release rate of ${ }^{137} \mathrm{Cs}$ from the existing basin sources. Assuming essentially $100 \%$ removal efficiency by the deionizers, the steady-state ${ }^{137} \mathrm{Cs}$ activity is estimated by the following:

$\mathrm{A}_{\mathrm{W}}=\mathrm{R} / \mathrm{Q}$

where

$\mathrm{A}_{\mathrm{W}} \quad$ is the steady-state ${ }^{137} \mathrm{Cs}$ activity of the water [Ci/gal]

$\mathrm{R} \quad$ is the total ${ }^{137} \mathrm{Cs}$ release rate into the basins and includes the contribution from the damaged fuel (i.e., $\mathrm{R}_{\mathrm{DF}}$ as calculated above) and from any other materials stored in the basin $(\mathrm{Ci} / \mathrm{hr})$

Q is the flow rate through the deionization system $[\mathrm{gal} / \mathrm{hr}]$

Given the ${ }^{137} \mathrm{Cs}$ release rate to the basin, this equation may be used to estimate the steady state activity of the basin water as a function of the flow rate through the de-ionization system. Calculations for the SRS L-Basin show that large inventories of damaged aluminum-based fuels can be stored in the basin without a significant increase in basin activity levels. ${ }^{2}$ The method can be applied to other SNFs by applying fuel-specific general corrosion rates and surface areas presented during degradation.

\section{FUEL/WATER INTERACTIONS}

Damaged SNF was routinely placed in canisters for interim storage to protect the storage facilities from contamination and to protect the SNF in the wet storage environment. These canisters were usually made from stainless steel or aluminum. Some SNF that could react with water was sealed in canisters with an inert cover gas to provide a dry, neutral environment for the SNF. The containers were then placed in wet basin storage. A fraction of these sealed containers have leaked and unintentionally exposed the SNF directly to water.

\subsection{Spent Nuclear Fuel-Specific Experience}

\subsubsection{Uranium Metal Spent Nuclear Fuel}

The uranium metal SNF within the DOE inventory contains many elements whose cladding was breached during reactor discharge, subsequent handling, or storage. Initial cladding failures varied from minor cracks to severed fuel elements. The reaction of exposed uranium metal with water produces uranium dioxide and hydrogen. This reaction is not a result of chemical impurity of the basin water. It is a chemical reaction of the water with the uranium metal. Uranium hydride forms from the available hydrogen, particularly where there is a limited amount of oxygen (see Reference 3). The lower densities of the uranium oxide and uranium hydride products relative to the uranium metal cause swelling of the 
material within the cladding and subsequent additional cladding damage. Additional water reaction then occurs with the newly exposed uranium metal. Each cycle of fuel-water reaction results in fission product releases and contamination of water in the canister or the storage pool. Examples of uranium metal SNF element damage after extended water storage are shown in Figure 3. In extreme cases, the uranium metal has also been known to completely oxidize and form a mud-like mixture with the water. ${ }^{4}$

The generation of high surface area uranium metal SNF fragments and uranium hydride necessitates additional measures during SNF drying, dry storage, and transportation because of the pyrophoric nature of these materials when exposed to air. As a result, degraded uranium metal fuels are stored and transported in inerted canisters after removal from the basin and drying. Radiolysis of water within the SNF-water corrosion products must also be addressed for long-term storage because of the ability of the resultant gases to overpressurize containers, embrittle welds on containers, and reach flammable concentrations.

\subsubsection{Sodium-Bonded Spent Nuclear Fuel}

Metallic sodium-bonded metal SNF has been stored underwater in an inert gas inside of sealed stainless steel canisters. Water ingress through leaks in canister fittings has resulted in water (containing

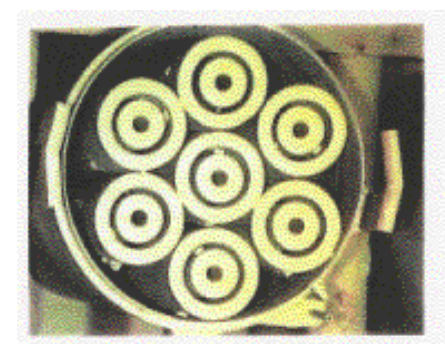

Intact Fuel

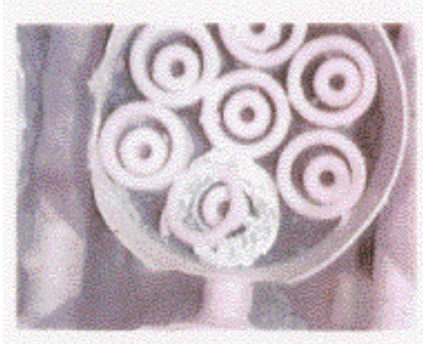

Detached End Cap

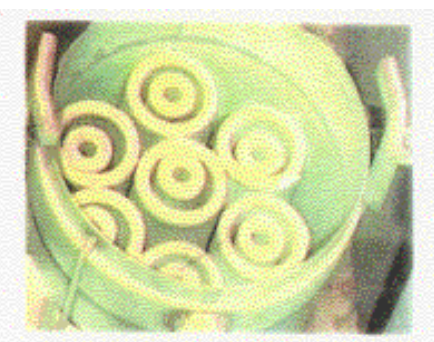

Small Rupture

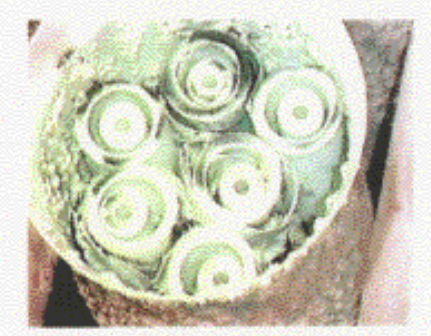

Split Cladding

Figure 3. Examples of uranium metal fuel damage.

chlorides) reaction with cladding and eventually with the sodium metal, producing sodium hydroxide and hydrogen gas. Ultrasonic testing at Materials and Fuel Complex, formerly Argonne National LaboratoryWest $^{5,6}$ and now a part of the INL, has indicated that further reactions with the SNF have resulted in complete degradation of the SNF material and production of a fuel sludge.

\subsubsection{Uranium Carbide Spent Nuclear Fuel}

Uranium carbide fuel is used in gas-cooled reactors. Uranium carbide material is highly reactive with water, and basin storage is, therefore, not a viable storage system. Uranium carbide SNFs have been stored in dry wells. The storage system did not adequately prevent condensation of water and subsequent metallic carbide-water reactions. Reaction products include acetylene and other hydrocarbons. At the 
INL, this situation was detected when off-gas measurements from Peach Bottom SNF in dry storage indicated the presence of flammable gas. The control strategy implemented is the periodic purging of the storage with replacement gas before flammable gas concentration reached levels sufficient to be a problem.

\section{SNF Drying}

Water is generally problematic for SNF storage (see Sections 2 and 3). However, most SNFs have been wet at some time in their life. Transfer to dry storage usually requires removal of the water during the handling and repackaging process. If water remains with the SNF configuration material interactions may result in SNF degradation and pressurization of the container. This requires deriving data on the amount of water in the SNF storage configuration and actions to remove the water, including physical drying of the SNF.

To effectively mitigate the hazards caused by water, the storage environment and water content in the SNF configuration must be understood. To accurately evaluate the effects of water in a SNF storage package, one must determine the amount of free water, free water, and chemically bound water in the configuration. Damaged SNF complicates this determination because of the additional potential for free, physically absorbed, and chemically bound water, to be retained in corrosion product and porous materials. A fuel's drying characteristics are also affected by its packaging (e.g., buckets, baskets cans), packaging geometry (e.g., corroded cylindrical can, inside a cylindrical overpack can with a rectangular flanged lid, inside a rectangular bucket), materials that comprise the packaging (e.g., stainless steel overpack can, aluminum inner can), and any other materials contained in the packaging with the SNF (e.g., water, basin silt, epoxy, corrosion products, biofilms).

\subsubsection{Need for Drying Standards and Supporting Data}

The amount of free water on a SNF can be difficult to determine because of complicated geometries, unknown porosities, and debris. Many SNFs types have multiple plates and crevices to trap water. Corrosion penetrations can allow water to enter pores in the fuel matrix and small gaps between the fuel matrix and cladding (e.g., corroded aluminum clad TRIGA). Debris, such as fuel pieces, container corrosion product, and basin silt, can trap water in fuel features or plug container drain holes.

Fuel configuration specific data that are necessary to determine physically and chemically adsorbed water content as a function of temperature and, to a lesser extent, pressure are difficult to obtain. The lack of fuel configuration specific data on physically and chemically bound water content and the temperature, pressure, and time required to free this water, has prevented water content from being accurately determined. Important factors affecting the amount of bound water in damaged fuel configurations are the:

1. Amounts and types of corroded materials (e.g., cladding, fuel matrix, containers, debris)

2. Corrosion layer thickness

3. Corrosion layer composition

4. Rate and extent of radiolysis of bound water

5. Amount and types of nonfuel materials (e.g., basin silt, bio-films, epoxy). 
Historically, applicable test data have been unavailable. Literature data on specific materials is sometimes available. Even when data are available on a specific material, it can be difficult to apply these data. For example, to estimate the bound water content of an aluminum clad SNF configuration, one must know the thickness of the aluminum oxide corrosion layer on the SNF element, the form of the aluminum oxide (bayerite, gibbsite, boehmite, etc.), the porosity of the corrosion layer, the other constituents in the corrosion layer (basin silt, bio-films), the amount of corroded aluminum from current or prior containers present, etc. Depending on various postulated accidents, the available data on the specific material may or may not meet the rigor necessary to ensure safe handling and storage of the damaged SNF. As a hypothetical example, if a sealed SNF container was limited to $2000 \mathrm{~g}$ of free water, had an internal void volume of about $205 \mathrm{~L}$, and the temperature was allowed to increase to $400^{\circ} \mathrm{C}$, the pressure could increase to 440 psia due to free water vapor. This increase does not take into account pressure contributions from bound water released, radiolysis, radiogenic gases, or inert backfill gases such as helium. For this scenario, the SNF container would have to be able to withstand this pressure, or the temperature and/or water content limits would have to be reduced accordingly.

As an example, consider an actual proposed disposal configuration for TRIGA SNF. The disposal configuration is in an 18-in.-diameter, 10-ft-long standardized DOE canister (see Section 9). This configuration has a void volume of about $205 \mathrm{~L}$. The SNF in this configuration has a mass of approximately $368,000 \mathrm{~g}$. One could reasonably assume a free water content of $2000 \mathrm{~g}$ because that would be less than $0.5 \%$ by mass. Also, the proposed disposal configuration includes $7200 \mathrm{~g}$ of gadolinium phosphate beads inside the canister to aid in criticality control. The $7200 \mathrm{~g}$ of gadolinium phosphate beads could contain over $900 \mathrm{~g}$ of physically and chemically bound water. ${ }^{7}$ If this bound water is released by temperature and/or radiolysis it could contribute nearly half of the assumed $2000 \mathrm{~g}$ water content limit.

Because packaging configurations and conditions like these are possible, adequate drying must be ensured before sealing damaged SNF in containers. Although difficult to obtain, these data may be necessary to ensure damaged SNF is properly dried before being sealed in canisters. In the absence of clear drying standards or supporting data, monitoring programs and engineered controls may be put in place to prevent excessive pressure.

\subsubsection{Repackaging Considerations and Strategies}

There are several issues to be considered when repackaging damaged SNF to reduce future problems and costs associated with drying the SNF. Significant quantities of the INL damaged SNFs were packaged in aluminum containers that were later placed into another overpack container. Some damaged SNFs were further over packed a second time in nondraining containers when the first package became compromised. (A description of TORY-IIA repackaging is in Appendix B) Overpacking adds thermal mass, may increase free water, may increase corrosion product, decrease storage density, and restrict removal of water; all of which complicate future handling. The list below summarizes key lessons learned from the DOE experiences that can impact removing water from damaged SNFs. These items should be considered when handling and repackaging damaged SNFs.

- $\quad$ Overpacking can restrict the pathway for water removal from the container and reduce the heat transfer when drying. Containers designed with more open structures improve heat transfer and allow convective airflow to help transport vapor from the container.

- $\quad$ Drying SNF solely by forced convection using heated gases is inefficient. Vacuum drying at elevated temperatures has proven to be most effective. Heating of the fuel configurations using conduction and radiant heat transfer principles has been the least costly and most efficient. 
- Drainable containers are advantageous when SNF is removed from water storage. This reduces the free water retained. A container design incorporating screened holes near the bottom has proven effective for several operations handling severely damaged SNF. The holes allow water to drain, and the screens help to retain degraded fuel material in the can. This can significantly reduce the amount of water that must be removed by the vacuum system.

\section{OXIDATION OF URANIUM DIOXIDE SPENT NUCLEAR FUEL}

DOE manages a variety of uranium dioxide SNF inventories that were used to support reactor development, enhanced SNF designs, spent fuel storage system development, and repository performance assessment activities. Most of this SNF inventory has intact cladding with no observed defects. In some instances, the SNF cladding is breached as a result of the testing activities. An estimated 2 to $4 \%$ of the SNF assemblies within the DOE inventory have at least one failed rod with breaches greater than pinhole leaks or hairline cracks.

\subsection{Factors Affecting Uranium Dioxide Oxidation}

A primary consideration for handling and storage of these SNF inventories is the potential for oxidation of the uranium dioxide fuel meat to $\mathrm{U}_{3} \mathrm{O}_{8}$ when exposed to oxygen at elevated temperatures. Oxidation occurs through pinhole leaks, hairline cracks, and gross cladding defects. Formation of the less dense $\mathrm{U}_{3} \mathrm{O}_{8}$ causes the fuel meat to swell and split the cladding, referred to as unzipping. This releases radioactive particulate and fission gases and exposes additional fuel for potential oxidation. Release of particulate from the cladding can affect criticality safety, control of contamination, worker exposure, and future SNF retrievability.

Time and temperature are the primary factors affecting the extent of oxidation. An apparent damage threshold has been observed at about $300^{\circ} \mathrm{C}$. At $350^{\circ} \mathrm{C}$, about $20 \%$ of a standard SNF rod has been observed to unzip in a period of 500 hours. At $400^{\circ} \mathrm{C}$, about $15 \%$ of a fuel rod has been observed to unzip in only 100 hours. Examples of cladding damage from unzipping are shown in Figure 4 from experiments at Pacific Northwest National Laboratory. ${ }^{8}$

\subsection{Cask Contamination}

Damaged SNF and damaged containers have the potential to contaminate transport casks. One such incident, discussed in detail in Appendix A, occurred in 1980. A NAC-1E cask, was loaded with a failed fuel assembly, which underwent further cladding degradation in transport. As a consequence of the cladding degradation, the cask was internally contaminated with spent fuel residue. The cask was filled with air when packaged. Delays in shipment, combined with errors in realizing the heat output from the $\mathrm{SNF}$, resulted in high temperatures within the cask. This high temperature facilitated the scavenging of oxygen from the air by the exposed fuel at the points of cladding failure, creating $\mathrm{U}_{3} \mathrm{O}_{8}$. This larger 


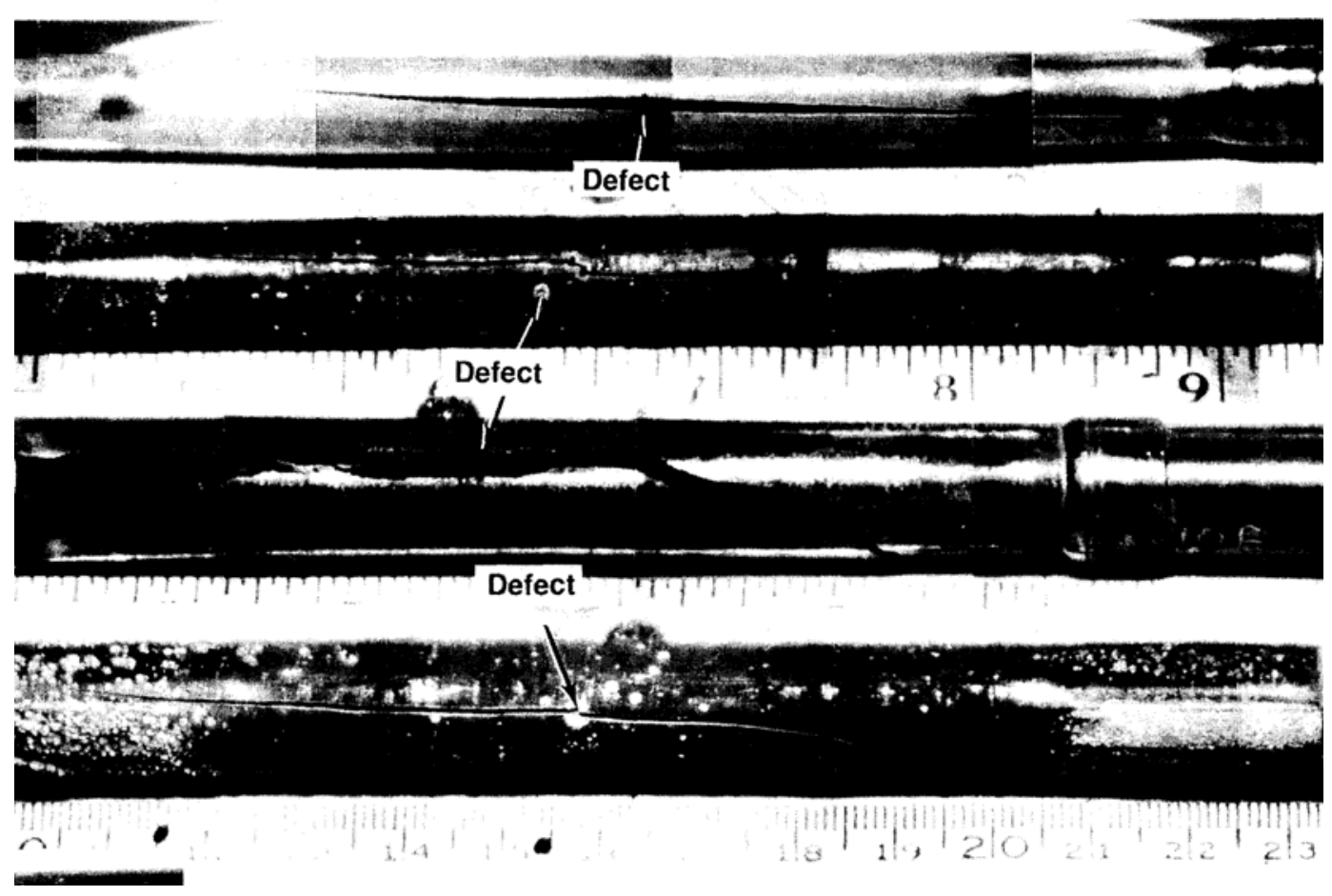

Figure 4. Examples of cladding damage for experiments at Pacific Northwest National Laboratory.

molecule enlarged the existing cladding breaks allowing this conversion of additional exposed fuel. This particular scavenging phenomenon was previously unknown. When the cask was received and unloaded, a contamination incident occurred because of the reaction of the SNF, air, and water. Because of handling issues, the cask sat idle for several years until it was cleaned with hydrofluoric acid and recertified for service. One result of this incident is the requirement for an inert gas to be used as a cover gas for SNF shipments.

\subsection{Uranium Dioxide Oxidation Control Measures}

To minimize the extent that oxidation of the uranium dioxide can occur, the following measures have been used at DOE facilities: (a) establishing time limits for exposure of fuel pins to air based on thermal analysis to minimize oxidation rates, (b) using inert environments in leak tight containers to limit access of oxygen to the fuel, and (c) maintaining wet storage of fuel until sufficient decay to limit storage temperatures. Where cladding failures have been observed, fuel has been canned and stored within an inert environment that ensures fuel particulate is maintained within a safe and retrievable configuration.

The measures to control uranium dioxide oxidation are important during all phases of spent fuel management, including storage, transport, and implementation of final disposition. The SNF is particularly vulnerable during transfer from one controlled environment to the next, such as during cask loading and unloading. Inerted hot cells may be used during these transfers when necessitated by the SNF decay heat and the amount of time to complete the transfer operation. 


\section{EXTENDED INTERIM STORAGE PERIODS}

A common difficulty for handling some damaged SNF is policy and scheduling changes that extend the planned interim storage duration or change the planned disposition. Through the years, DOE has received nuclear materials from many locations and reprocessed the material to recover the fissile materials. The interim material storage conditions were based on the criteria that the material would only be in storage for a short time. Therefore, the storage environment and conditions often did not address long-term storage issues and requirements. For example, as storage periods were extended, many fuels were moved from wet to dry storage. The issues associated with dry storage were often not considered when fuels were packaged. The inclusion of extraneous materials with the SNF and the design of lifting and handling fixtures are examples.

\subsection{Container Materials}

Damaged SNF was intentionally placed into temporary containers that were compatible with the reprocessing dissolvers rather than containers designed for long-term storage. Aluminum was often selected for storage containers because it would facilitate reprocessing of the contained SNF in a dissolution process. However, aluminum proved to be a problem when water quality was not maintained and storage durations were extended. When reprocessing operations were delayed, the containers corroded, and the degraded SNF was exposed to the wet storage environment. As storage of these materials was extended, often more than once, the design life of the container or SNF cladding often became problematic. In many of these cases, the original container was placed in another container. In a few cases, the second container degraded to the point of requiring placement in a third container. This container compounding was a stop-gap measure, and that did not correct the original problem. These multiple packages will increase repackaging costs at the time of disposal because of the need to open each container to perform final packaging for disposition.

Experience has also shown that corrosion allowances require careful evaluation during planning for the storage and are dependent on the term of the storage, the storage environment, and should include an allowance for storage beyond the planned storage period to provide some margin for change to the planning basis. For example, based on current legal requirements to remove all DOE SNF from Idaho by 2035 , the INL is currently planning movement of SNF to interim storage through 2035 and is creating an appropriate corrosion allowance on storage canisters to support that storage period.

\subsection{Extraneous Materials}

Extraneous materials placed in SNF canisters can cause difficulties when preparing the SNF for interim storage or disposal. There have been cases of items such as gloves, debris, and other materials being inadvertently placed in a canister, creating downstream difficulty with repackaging, drying, or other operations. At a minimum, such material creates excess contaminated material to be disposed of.

One such example is the use of epoxies to stabilize disrupted or sectioned fuel pieces. Stabilization is sometimes required for handling the fuel pieces during and after postirradiation examinations. In dry storage and in handling conditions, epoxy can affect the nuclear reactivity of a SNF package. Epoxy also has implications for toxicity and flammability at elevated temperatures required for water removal and may affect the acceptability of the SNF for disposal. Further, the characteristics of epoxy compounds in various handling and storage conditions, such as radiation fields and high temperatures, are not well documented. As an example, it is understood that the formation of hydrogen and phenol are potential hazards when the compounds are at elevated temperatures but the nature of off-gasing has not been fully examined and documented. 
Conclusive evaluations on the effects of epoxies for the previously stated conditions can be further complicated by the use of different types of epoxies, each having their own unique performance characteristics in radiation fields and high temperatures. As an example, at one DOE examination facility, at least seven different types of epoxy compounds (Armstrong, C-7, Spurr, Buehler, Dow Epoxy Resin, Araldite, and Acme Maraglass) and a phenol compound (Bakelite) were used in various testing programs. The damaged fuel pieces were combined without segregation and often without into storage containers.

This situation has been problematic for handling and storage and may also complicate strategies for disposal of the damaged SNF. Other materials that may become problematic in fuel packages are desiccants and grouting mixtures. This issue shows the need for foresight and careful consideration when combining damaged SNFs with extraneous materials.

\subsection{Lifting and Handling Fixtures}

Fuel rods or assemblies are typically designed to include an integral lifting and handling fixture. SNFs that are otherwise undamaged sometimes have their lifting fixtures removed. Cropping of lifting fixtures and other nonfuel items from an element or disassembling an element often was done to conserve SNF storage space, to fit the SNF into specific shipping containers, or to allow the SNF to be studied. Historically, this was often done to reduce the amount of non-SNF material that had to be dissolved when the SNF was reprocessed, thus reducing the processing time and high-level liquid waste generated.

SNFs that have intact cladding, but have had their lifting fixtures removed, present several unique issues and challenges. Cropping or disassembly criteria were often based on a specific facility with specific SNF handling capabilities. For example, the cropping criteria may be developed for underwater handling where operators can control handling tools hands-on. However, when the SNF is moved to a hot cell where all operations are remote, the lack of in-cell dexterity severely hinders the SNF handling operations. Similarly, many lid designs have the canister lifting fixtures affixed to the lid. When the container lid is removed, the lifting fixture is lost, and handling the canister becomes a challenge.

An example of this is the case where end boxes are cut from plate type SNFs. In most of these cases, the fuel can be picked up in a storage basin with some specific methods and tools that only minimally increase operational difficulty. However, most fuels will eventually be moved to dry interim storage, and the same methods are generally not effective in a remote environment where operations involve mechanical or electromechanical manipulators that lack the dexterity and reliability of underwater tools, thus increasing operational difficulty. These challenges can be avoided with proper foresight and consideration when modifying fuel element lifting fixtures.

During dry cell operations, the consequences of dropping damaged SNF or a SNF package are usually more severe, and the recovery efforts are more difficult than underwater. Whenever possible, remote lifting tools should be designed with positive latching mechanisms that allow visual verification of proper latching. Like the positive latching and visual verification required for the tool to the SNF, the tool should also be positively latched with visual verification, to the lifting device to which it is attached. The design of such tools can further be a challenge where space and visibility is limited around fuel elements. A further challenge is to design tools that can recover from scenarios wherein the tool's releasing mechanism fails and the tool cannot be released from the fuel lifting fixture. DOE facilities have developed several methods to ensure these functional requirements are safely met. Examples are providing redundant and independent release mechanisms and at least two independent methods for doing all remote activities.

The difficulty of meeting the above-mentioned tool design constraints is compounded by having many different types of damaged fuel elements and many different fuel container lifting fixtures with 
container specific tools. In many cases SNF has to be received by facilities with little or no input on the design of the lifting and handling fixtures. This necessitates designing unique remote handling tools for each distinctive lifting fixture and sometimes requires tools to be changed frequently during a SNF handling operation. Effective interfaces and early interaction between shipping and receiving facilities can significantly improve tool design and operational effectiveness.

\section{MATERIAL ACCOUNTABILITY AND RECORD KEEPING}

Fundamental to accounting for and controlling of nuclear materials are fuel item identification, item weighing (mass), and nondestructive assay — either through confirmatory measurements or accountability/verification measurements. Performance of these actions is essential to ensure that the fuel item identification numbers and their associated nuclear material quantities are physically present.

The situation exists where identification numbers on damaged fuel elements have been corroded or damaged. As an example, some aluminum clad TRIGA elements were corroded such that the end caps that had the identification numbers had fallen off the elements. This issue was addressed by combining elements into a new package and creating appropriate records to ensure that accountability was preserved.

Another accountability issue arises for more severely damaged fuel elements where accountable material may have degraded to debris or even sludge. In such cases, accountability requirements are challenging without the capabilities to perform confirmatory measures on the material during handling. The problems can be further complicated where the repackaging has not previously (or cannot now) be done one for one. In other words, the debris from the original container is not repackaged entirely into another container. If contents must be separated or combined with the contents from different containers, the accountability process may require additional constraints or controls on the packaging and associated records unless the proper equipment to weigh and characterize the materials is available. While all material is still accounted for overall, the specific distribution of material per package within a set of containers may be questionable. Further, assigning conservatively high fissile values to each container for safety basis purposes increases handling and disposition costs.

Unirradiated, slightly irradiated, and moderately irradiated fuel elements are susceptible to performance of measurements using current nondestructive assay methodologies. Neutron interrogation methods for confirmatory measurements are available for highly irradiated fuels. However, efforts to reduce dose levels to operators and measurement personnel require further development for improved fuel handling isolation and dose mitigation designs within facilities before the current interrogation capabilities can be effectively implemented.

\section{CANISTER DESIGN FOR DAMAGED SNF}

Experience has shown that special design features for the canister may be needed, dependent on the SNF type and condition. Damaged/degraded cladding or structural features of a SNF assembly, if significant, can result in radiological, criticality safety, waste, and accountability issues. Placing the damaged SNF assembly in an isolation canister has been a common solution to prevent these more widespread problems. The canister provides necessary design features that were once performed by the SNF structure and cladding. Design features and considerations relevant to canisters for damaged SNF isolation are presented in Appendix C. 


\section{STRATEGIES FOR THE FUTURE}

The United States is preparing for disposition of much of its SNF inventory, including damaged SNFs, in the Monitored Geologic Repository currently under development at Yucca Mountain in the state of Nevada. Detailed analysis and design activities are required to prepare and submit a license for the repository to operate under license from the Nuclear Regulatory Commission.

The major disposition strategy supported by these analyses is use of the DOE standard canister to facilitate interim storage, handling, and eventual disposal of a wide variety of DOE SNFs. Design considerations for standardized canisters include items such as canister survivability, the need for neutron absorbers, and radiological source term evaluations of the canister contents. Standardized canisters not only provide for a standardized package to facilitate handling, transport, and disposal of a wide variety of spent nuclear fuels, they also provide a containment boundary that significantly reduces the need for detailed characterization of the canister contents in subsequent analyses. The description of these canisters and the analyses that support their design and other licensing information are discussed in the following sections.

\subsection{General Canister Descriptions}

The term "standard canister" is used to refer to 2 canister designs. The first of these, the DOE standardized canister will accommodate most the DOE SNF intended for disposal in the repository. The second of these is the Multi-Canister Overpack (MCO) used by Hanford for packaging of N-reactor SNF. Both of the containers are intended to provide uniform handling requirements for design of the repository facilities, simplifying handling operations at the repository. The SNF would be packaged at the specific sites into the standard canisters, using any required fuel-specific tools at that site. When shipped to the repository, these sealed canisters would all have the same handling design, eliminating the need for fuel-specific handling tools for each SNF.

The DOE standardized canister was developed to minimize the need for repacking and to standardize fuel handling during interim storage, transport, and final disposal operations. The canister incorporates an energy absorbing skirt that protects the top and bottom heads and shell during a potential drop or sudden impact. The standardized canister is sufficient to withstand operational loads and accidental drops while maintaining containment and to serve as an interim storage package.

The MCO was initially designed for interim storage to satisfy a near-term need to move the $\mathrm{N}$-reactor fuel from water basin storage. DOE has since demonstrated that the MCO can meet the operational loads and accidental drops at the repository surface facility and will be analyzing the MCO for transportation loads in the near future.

The overall integrity of the DOE standardized canister and MCOs have been demonstrated through analytical modeling and multiple drop tests at varying impact angles followed by helium leak testing. The DOE standard canisters are a key component in the licensing strategy for DOE SNF. By demonstrating the integrity of the standard canisters for maintaining confinement, safety analysis became relatively independent of the canister contents (i.e., no radiation release from the canister). Thus a wide variety of SNF, including damaged SNF and SNF that is not characterized fully to Nuclear Regulatory Commission standards can be stored, transported, and disposed of without the need to perform detailed characterization. DOE Standard canisters are more fully described along with supporting analyses, tests, and conclusions relative to its survivability under possible future scenarios are documented in Reference 9 and briefly summarized below. 


\subsubsection{Material Interaction}

Material interactions considered for the DOE standard canister included the chemical, physical, and thermodynamic properties of the materials to be stored in the canisters. Degradation mechanisms that were considered include electrochemical interactions such as general corrosion, pitting corrosion, and stress corrosion cracking; mechanical forces, such as overpressurization; and metallurgical degradation such as hydrogen embrittlement, liquid metal embrittlement, and thermal effects due to welding. It was concluded that, if properly dried, there are no significant degradation mechanisms that would cause failure of a standardized canister or MCO at nominal repository temperatures of $200^{\circ} \mathrm{C}$ or even as high as $350^{\circ} \mathrm{C}$. It was further concluded that neither the proposed DOE standardized canister constructed of Type 316L stainless steel nor the MCO made with Type 304L stainless steel is expected to be susceptible to liquid metal embrittlement due to the presence of cesium and rubidium from the fuel. The canister shells are immune to stress corrosion cracking from cesium/rubidium hydroxide based on the experiments performed by the National Spent Nuclear Fuel Program. After drying and inerting, the DOE standard canister degradation is considered negligible.

\subsubsection{High Strain Testing}

A design requirement for the use of the DOE standard canister is to maintain confinement after a drop of 23 feet. This requirement is dictated by the maximum lift height during interim storage and subsequent handling in the repository surface facility. An evaluation was performed to demonstrate that these drops could be reliably modeled on computers using finite element analysis using ABAQUS/Explicit software. The use of finite element analysis for elastic structural response has been successfully used in numerous industries including the nuclear power industry. Additional testing was necessary, however, to obtain a similar level of confidence for plastic analysis technology. Numerous drop tests have demonstrated that the standardized canister meets the 23-ft drop requirement and have also validated the computer modeling effort. ${ }^{10,11}$

The effort to model the drop accidents included development of material data to support modification to the stress-strain curve to account for strain rate effects under moderate strain rates. This material data will be based on limited dynamic material testing at strain levels and strain rates approximating what the DOE standard canister is expected to experience during accidental drop events. These strain and strain-rate values will be determined from the applicable canister analytical evaluations performed to date, which used plastic analysis techniques using ABAQUS/Explicit software.

\subsubsection{Thermal Analysis}

Two thermal analyses were performed to evaluate the allowable decay heat values that could be supported by the DOE standardized canisters. The first analysis determined the allowable decay heat value that could be supported by the DOE standardized canister oriented vertically in ambient air at $21^{\circ} \mathrm{C}$ $\left(70^{\circ} \mathrm{F}\right)$ The second analysis determined the allowable decay heat value such that under steady state conditions with nine DOE standardized canisters arranged inside a transportation cask, a maximum temperature of $316^{\circ} \mathrm{C}\left(600^{\circ} \mathrm{F}\right)$ occurs in the stainless steel wall of any DOE standard canisters. These analyses determined administrative controls needed during the transportation of the DOE standardized canister in a cask.

\subsection{Advanced Neutron Absorber Development}

Researchers are developing a corrosion-resistant, nickel-chromium-molybdenum alloy containing gadolinium for criticality control in the DOE standard canister. Gadolinium has a very high neutron absorption cross section. The gadolinium must be alloyed into a corrosion-resistant structural metal that 
will meet ASME, Section 2 code requirements to be used as a structural material. This alloy may be used for the internal baskets of the DOE standardized canister to provide structural support and geometry control and to ensure nuclear criticality safety. Use of poison inside the canister allows higher fissile loading per canister and provides additional safety margin to accommodate uncertainties associated with damaged or poorly characterized SNF. This will reduce the number of canisters and waste packages needed for DOE SNF disposal. Researchers are working to define the chemistry ranges and minimum mechanical properties for the ASME code case.

\subsection{Fuel Grouping}

The DOE SNF Spent Fuel Database, maintained by the National Spent Nuclear Fuel Program with input from the individual SNF sites, includes nearly 600 records representing many different SNF types with varying operational and storage histories. This posed a challenge in the number of analyses needed to support repository design and licensing. The necessary analyses were simplified by categorizing the DOE SNF into fuel groups that share properties relevant to preclosure safety analysis, postclosure total system performance assessment analysis, and criticality analysis. DOE SNF was grouped by similar materials of construction, fuel properties, etc., to arrive at a manageable number of representative groups for analyses. ${ }^{12}$

\subsection{Source Term Development}

In order to enable final disposition of SNF, source terms must be provided to support analyses for the proposed Monitored Geologic Repository at the Yucca Mountain Site. Source term calculations provide estimates of radionuclide inventories that are used in the calculation of decay heat for thermal analyses of casks and storage canisters, photon emission spectra for shielding calculations, fissile inventory for criticality safety evaluations, and radionuclide doses associated with preclosure and postclosure repository safety analyses.

DOE SNFs come from a wide range of reactor types (such as light and heavy water moderated reactors, graphite-moderated reactors, breeder reactors) with various fuel compounds, cladding materials and enrichments. Many of these reactors, now decommissioned, had unique design features such as core configuration, fuel element and assembly geometry, reflector and coolant materials, operational characteristics, and neutron spatial and spectral properties. Although these fuels have been safely handled and stored for many years at DOE storage facilities, historical data, such as fuel fabrication, operations, and storage records, are incomplete or questionable for many of these fuels. If needed to demonstrate compliance with repository license criteria, existing data may not meet current quality assurance requirements. Characterization of these fuels would be extremely costly. And an individually calculated radionuclide inventory for each fuel would require a substantial calculational effort with results that would inherit the uncertainty of the inputs. As an alternative, a methodology that relies on minimal information for developing a conservative source term estimate for DOE SNFs was developed.

The source term methodology was developed by a team of experts representing each DOE storage site. The methodology is based on calculational techniques that have been successfully applied at the storage sites ${ }^{13}$ supplemented by the application of similarity principles to bin fuels into groups that can employ precalculated ORIGEN outputs to model the generation of activation products and transuranics at a range of decay times. ${ }^{14}$

By modeling various combinations of reactor moderator, fuel enrichment, fuel compound, and fuel cladding, templates have been developed to reasonably model a broad range of DOE SNF. These templates provide inventories for 145 radionuclides at 10 different decay periods, ranging from 5 to 100 years following irradiation. To estimate a SNF source term, an appropriate template is selected to 
model the production of activation products and transuranics by matching four selected parameters (reactor moderator, the fuel cladding, the fuel compound, and the fuel enrichment). Conservative assumptions can be applied if one or more of these four parameters are unknown. Precalculated radionuclide inventories are extracted from the selected template at the desired decay period and then scaled to account for differences in fuel mass and specific burnup. If burnup information is not available, conservative assumptions are used. Consequently, the methodology includes an algorithm for estimating burnup, using available information that, in some cases, may consist of no more than the end-of-life heavy metal mass.

Because it can be employed to conservatively estimate radionuclide inventories and the associated source term, decay heat, and photon emission rate for virtually any SNF, this source term estimating methodology may also be useful to support design and safety considerations associated with damaged or poorly characterized spent fuel. 


\section{REFERENCES}

1. IAEA, "Corrosion of Research Reactor Aluminum Clad Spent Fuel in Water," Technical Reports Series 418, 2003.

2. D. W. Vinson, R.W. Deible, and R.L. Sindelar, "Impact of Degraded Al-SNF on Shipping and Basin Storage," ANS Topical Conference, Charleston, SC, 2002.

3. A. B. Johnson, Jr. (Pacific Northwest Laboratory) and S. P. Burke (Westinghouse Hanford Company), K Basin Corrosion Program Report, WHC-EP-0877, September 1995.

4 T. L. Welsh (Protection Technology Hanford), P. R. Bredt, G. R. Golcar, A. J. Schmidt, K. L. Silvers, J. M. Tingey, A. H. Zacher (Pacific Northwest National Laboratory), R. B. Baker and B. J. Makenas (DE\&S Hanford, Inc.), Analysis of Internal Sludge and Cladding Coatings from N-Reactor Fuel Stored in Hanford K Basins, HNF-3589, June 1999.

$5 \quad$ Robert G. Pahl, "Degradation of EBR-II Driver Fuel During Wet Storage," ANS Fourth Topical Meeting, DOE Spent Nuclear Fuel and Fissile Material Management, San Diego, CA June 4-8 2000.

6 Robert G. Pahl and Emil M. Franklin (Argonne National Laboratory-West), and Matt A. Ebner (Lockheed Idaho Technologies Co.), "Technical Assessment of Continued Wet Storage of EBR-II Fuel," 1996 DOE Spent Nuclear Fuel and Fissile Material Management Conference Reno, Nevada, June 16-20, 1996

7 P. A. Lessing and A. W. Erickson, "Synthesis and Characterization of Gadolinium Phosphate Neutron Absorber," Journal of the European Ceramic Society 23, February 1, 2003, pp 3049-3057.

8. U.S. Department of Energy, Office of Civilian Radioactive Waste, Clad Degradation-Dry Unzipping, Rev. 0, ICN 00, ANL-EBS-MD-000013, April 2000.

9. $\quad$ BSC, U.S. Department of Energy Spent Nuclear Fuel Canister Survivability, 000-PSA-WHSO00100-000-000, Bechtel SAIC, July 2004.

10 D. K. Morton, S. D. Snow, and T. E. Rahl, "FY 1999 Drop Testing Report for the 18-Inch Standardized DOE SNF Canister," EDF-NSNF-007, Rev. 2, September 2002.

11 D. K. Morton, S. D. Snow, "Drop Testing Representative 24-Inch Diameter Idaho Spent Fuel Project Canisters," EDF-NSNF-045, Rev. 0, January 2005.

12. U.S. Department of Energy, Environmental Management, DOE SNF Grouping in Support of Criticality, DBE and TSPA-LA, DOE/SNF/REP-046, Revision 0, May 2000.

13. U.S. Department of Energy, Environmental Management, Methodologies for Calculating DOE Spent Nuclear Fuel Source Terms, DOE/SNF/REP-055, January 2000.

14. U.S. Department of Energy, Environmental Management, Guide for Estimating DOE Spent Nuclear Fuel Source Terms, DOE/SNF/REP-059, July 2000. 
Appendix A

NAC-1E Event Chronology 
A-2 


\section{Appendix A}

\section{NAC-1E Event Chronology}

In July 1980, the NAC-1E cask, which was operated by the (then) Nuclear Assurance Corporation (now) NAC International (NAC), was loaded with a failed fuel assembly, which underwent further cladding degradation in transport. As a consequence of the cladding degradation, the cask was internally contaminated with spent fuel residue. The documentation surrounding this event is very limited as it was sealed in the settlement agreement between the affected parties. The dates used in this summary are approximate.

In July 1980, the NAC-1E cask was loaded with a fuel assembly classified as failed (greater than pinhole leaks or hairline cracks in the fuel cladding), at the Connecticut Yankee reactor. The cavity was filled with air (not an inert gas) for transport. The failed fuel and air cover gas configuration was an authorized fuel configuration by the then current Certificate of Compliance 6698. The Certificate further limited the thermal output of the transported fuel to less than 2,000 watts.

Following loading, and in preparation for transport, it was found that the external radiation limits of the cask exceeded the value allowed by transport regulations $(10 \mathrm{mrem} / \mathrm{hr}$ at $10 \mathrm{ft})$. At that time, Conneticut Yankee verified the assembly parameters and determined that with the assistance of NAC, an exemption to use external shielding would be requested. This exemption was obtained, but delayed the immediate transport of the fuel to the Battelle Memorial West Jefferson facility (Battelle) where the fuel was to be evaluated to determine the cause of the cladding failure.

Transport to Battelle was uneventful. The cask was received at Battelle and handled normally. During the unloading process, Battelle personnel loosen the cask closure lid and filled the cask with water. The cask was lowered into the Battelle unloading pool (approximately 40 feet deep, with the top of the cask approximately $23 \mathrm{ft}$ underwater) and the lid was removed. On removal of the lid, a column of "hot" water rose to the surface of the pool. The cask cavity water was hot (approximately $200^{\circ} \mathrm{F}$ ) relative to the unloading pool water temperature (approximately $80^{\circ} \mathrm{F}$ ) and had entrained in it a significant (very large) quantity of fuel particulate. A significant portion of that particulate became airborne, which severely contaminated the unloading pool area.

Battelle personnel, after taking some recovery actions, completed unloading the cask and transferred the failed fuel to a storage rack.

Subsequent investigation showed that the thermal output, and radiological source term, of the fuel assembly exceeded that authorized by the certificate of compliance. As a consequence of the higher heat load, the hottest (center) fuel rod was estimated to have reached a temperature of approximately $430^{\circ} \mathrm{C}$. This high temperature facilitated the scavenging of oxygen from the air by the exposed fuel at the points of cladding failure, creating $\mathrm{U}_{3} \mathrm{O}_{8}$. This larger molecule enlarged the existing cladding breaks allowing this conversion of additional exposed fuel.

[Note: This particular scavenging phenomenon was previously unknown. The demonstration of its occurrence by this event caused the Nuclear Regulatory Commission to revise all spent fuel cask certificates to require the use of an inert gas (helium, argon or nitrogen) as a cover gas in spent fuel shipments.] 
Upon flooding the cask with water in preparation for placing it in the unloading pool, there was a spalling of the fuel material from the fuel rods as the water converted to steam, and the fuel material subsequently became highly mobile. Both a high temperature and a high radiation level were evidenced at the vent line of the cask, which discharged into the unloading pool. Use of the open vent line precluded any significant pressure buildup in the cask cavity during the flooding process. In addition, the lid of the cask was loosened ( 4 of 6 bolts removed, 2 finger tight), and the cask pressure rupture disk and pressure relief valve were in place and operational. These conditions prevented the cask cavity pressure from approaching the design limit (1,100 psig). Based on evaluation of the water flow rate and vent line operation, the cask cavity pressure during flooding was estimated to be approximately $50 \mathrm{psig}$.

In its evaluation of the NAC-1E event, NAC determined that

- $\quad$ The maximum temperature reached by the fuel (approximately $430^{\circ} \mathrm{C}$ or $800^{\circ} \mathrm{F}$ as determined by Battelle) was much less than the maximum temperature considered in the safety analysis report (SAR) $\left(1038^{\circ} \mathrm{F}\right)$

- The maximum internal pressure was 98 psig, which is less than the pressure considered in the SAR of 157 psig

- $\quad$ The estimated thermal output 2,300 watts, was greater than that allowed for transport without water in the cavity, but much less than the thermal output considered in the SAR $(12,400$ watts).

Consequently, NAC concluded that, other than the gross internal and external contamination that precluded use of the cask, none of the cask parameters considered in the SAR were exceeded.[Note: External contamination occurred because the cask was submerged in the unloading pool.]

After unloading and removal of the cask from the unloading pool, considerable effort was made to clean the cask of fuel debris in order to return it to service. Following some level of decontamination, Battelle directed that the cask be transported to another reactor in late July 1980. That reactor declined to use the cask based on higher than expected radiation readings at the vent and drain ports.

In late August 1980, the NAC-1E cask was transported to a commercial facility in California for additional internal decontamination and the replacement of seals, o-rings and valves. Following the completion of this work, the cask was transported to a reactor in California for transport of fuel from the reactor to the General Electric Morris facility in Illinois.

Based on high radiation readings and samples at the California reactor, it was determined that the residual levels of transuranic contamination within the cavity were still too high to allow opening of the cask in the reactor spent fuel pool. Based on this assessment of the condition of the cask, NAC reached agreement with the Sandia National Laboratory for the long-term storage of the contaminated cask at Sandia. This action effectively removed the NAC-1E from service.

[Note: The opening of the cask in a commercial reactor spent fuel pool would have caused the pool walls and hardware, the pool water filters and the resin columns to be contaminated with spent fuel residue. In the commercial sector, there is no disposal facility that accepts material that is contaminated with transuranics. Consequently, it was considered unreasonable to risk contamination of plant equipment and material with fuel debris.] 
The NAC-1E remained out of service at Sandia until March 1987. At that time, NAC contracted with the Department of Energy (DOE) to use the cask (provided that it could be returned to service) in the return of metallic fuel from a foreign research reactor. In the course of preparing the cask for transport from Sandia to the Savannah River Plant (SRP), it was determined by test that the o-rings in the cask lid had failed. Because there was no facility at Sandia capable of handling the cask (DOE casks are typically much smaller than commercial casks.), a decision was made to weld the cask closure lid to the cask body. This weld was a seal weld (not a structural weld) that had no effect on the performance of the cask. The cask was transported to SRP in April 1987.

At SRP, the cask was externally decontaminated, and the lid weld was removed by grinding. The interior of the cask was decontaminated using a hydrofluoric acid bath. This procedure removed all traces of the transuranic contamination. [Note: This process was not available outside of DOE facilities.] Because the grinding operation to remove the weld resulted in a beveled edge on the lid of the NAC-1E that did not look exactly like the drawing, the beveled edge lid was licensed by the Nuclear Regulatory Commission as an alternate lid configuration. The welding of the lid, and the subsequent qualification of the beveled configuration, was also carefully reviewed by the DOE prior to the authorization that allowed use of the NAC-1E in the foreign reactor fuel transport program. The DOE review showed that the weld operation that was performed, the weld removal, and the cosmetic repair of the lid (resulting in the bevel) and cask top surface had no effect on the performance or operation of the cask.

Following completion of the decontamination, NAC replaced some components and performed the necessary tests to show that the cask met all the conditions of its Certificate. [Note: In 1985, the Nuclear Regulatory Commission withdrew Certificate of Compliance 6698 and issued Certificate of Compliance 9183. This change in certificates was not related to the NAC-1E event. It occurred primarily as a condition of the licensing of casks for transport of the metallic fuel that would be moved in the foreign research reactor program.]

On October 26, 1987, NAC advised the Nuclear Regulatory Commission that the NAC-1E had been repaired, tested, and returned to service in accordance with the conditions of its certificate. 
Appendix B

\section{Tory IIA Fuel and Packaging Description}


B-2 


\section{Appendix B}

\section{Tory IIA Fuel and Packaging Description}

The Tory fuel was used in a test reactor intended to propel a military missile with a nuclear ramjet. The theory was that air, forced into a duct as the missile flew, would be heated by the reactor, causing it to expand and exhaust out the back and provide thrust. The code name for the missile was Pluto. Tory was the code name for the propulsion reactor. Tory IIA was the first reactor design. Project Pluto was initiated in 1955, and the reactor first achieved criticality in May 1961. The fuel was shipped to the Idaho National Engineering Laboratory (now the Idaho National Laboratory [INL]) from 1962 to 1964.

Fuel properties. The fuel was fabricated as ceramic fuel tubes composed of beryllium oxide. The tubes had a hexagonal cross section about $7 \mathrm{~mm}$ across flats. The reactor contained over 100,000 of the fuel tubes. After the critical experiments, the fuel tubes were removed from the reactor core and crushed to particles varying in size from $5 \mathrm{~cm}$ to 10 microns. The crushed fuel was then compacted into the shipping containers.

Fuel Package Description. Prior to shipment to the INL, the crushed fuel elements were placed in "primary shipping containers made" of 21.188-in.-long 6061-T6 aluminum tubing. The tubing has a 4-1/2-in. outside diameter and a 0.188 -in.-thick wall with a 0.125 -in.-thick bottom plate welded in place. After many years of water storage, the aluminum cans were found to be severely corroded and leaking. Therefore, each of the primary shipping containers was placed into an open-top fuel storage bucket for Tory IIA fuel cans to maintain configuration. The fuel storage bucket is made from 5 -in.-outside diameter aluminum tube with a 0.125 -in.-thick wall and a welded bottom plate. Then prior to transfer to another basin storage facility, the fuel storage buckets containing the original primary shipping containers were overpacked into new stainlesssteel cans. These new cans are 52.4 in. long and made of 5-in. Schedule 10 pipe. The can has a bolted plate for a lid with a pivoting bail. The lids do not seal, and the cans are full of water. The cans have no drain holes. 
Appendix C

Canister Designs 


$$
\text { C-2 }
$$




\section{Appendix C}

\section{Canister Designs}

\section{CONTAINMENT DESIGNS}

\subsection{J-tubes}

Many damaged spent nuclear fuel (SNF) canisters are designed to facilitate continued wet storage of the fuel while containing the radionuclide activity that can be released from breached cladding. Containing the released activity is important from the standpoint of radiological protection of personnel and waste generated by more frequent replenishment of basin deioinizer resin beds, which are caused by higher basin water activity levels. A common design feature for these cans was a J-tube in the lid of the canister (Figure 1). The J-tube is similar to a P-trap on a household sink. Once sufficient gases that are released from the damaged SNF and generated from radiolytic decay build up at the top of the can, the internal water environment becomes separated from the main basin.

J-tube designs have evolved to incorporate operational improvements. The original design of the tube made it susceptible to buildup of silt. As such, it was unknown if the tube remained unobstructed. The original design was also subject to activity release during handling because of a loss of the gas pocket. Once the gas pocket was gone, it could take a number of weeks before enough gas would build back up to isolate the canister internals from the main basin, while releasing some activity. The last canister designed used a modified version of the J-tube (Figure 2). As can be seen the tube/passage is inverted and not susceptible to silt buildup. Also, it takes very little gas buildup to separate the two water environments.

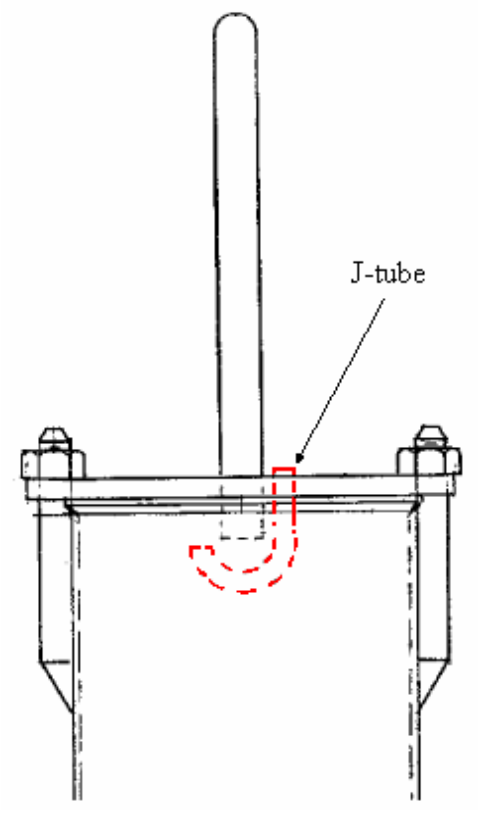

Figure 1. Old style J-tube design. 


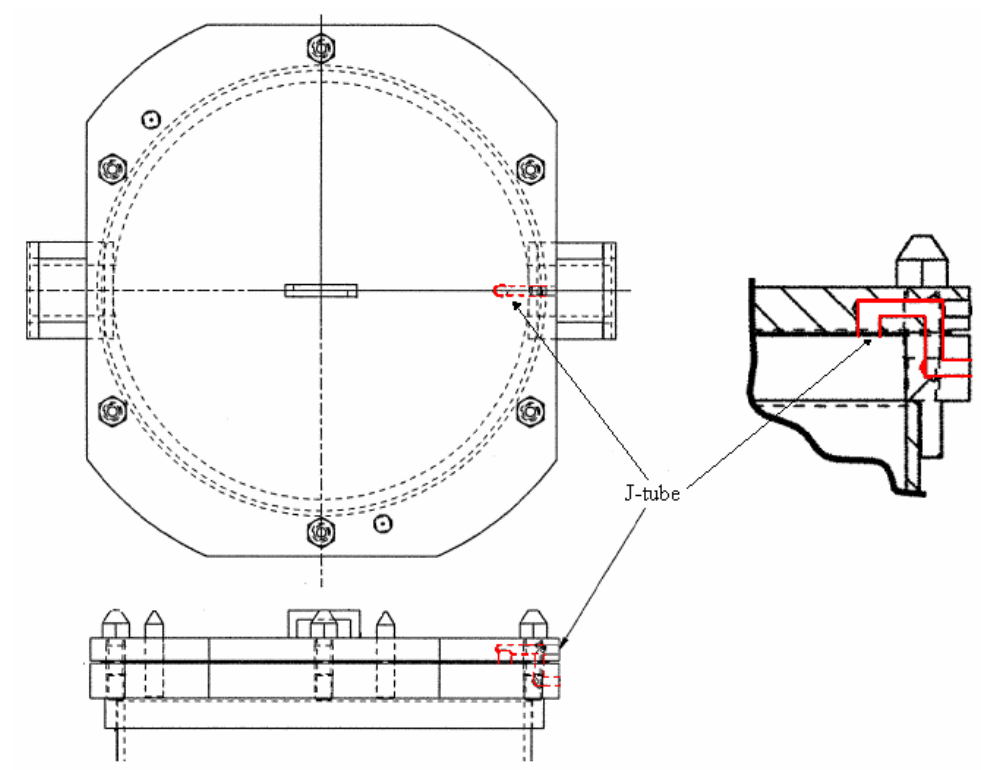

Figure 2. Latest J-tube design used on oversized can.

\subsection{Zeolite Storage Canister}

A more effective means for containing radionuclide activity generated from damaged or corroded SNFs has been developed and used. This design modifies a standard storage canister to receive a zeolitefilled lid. This design (Figure 3 ) is effective in containing radionuclide activity while preventing a buildup of flammable gases generated by radiolysis of the water within the canister. The zeolite acts as an ion exchange medium between the storage pool (low activity water) and the water (high activity) within the canister. Flow through the bundle is achieved via the thermal gradient created by the decay heat of the SNF.

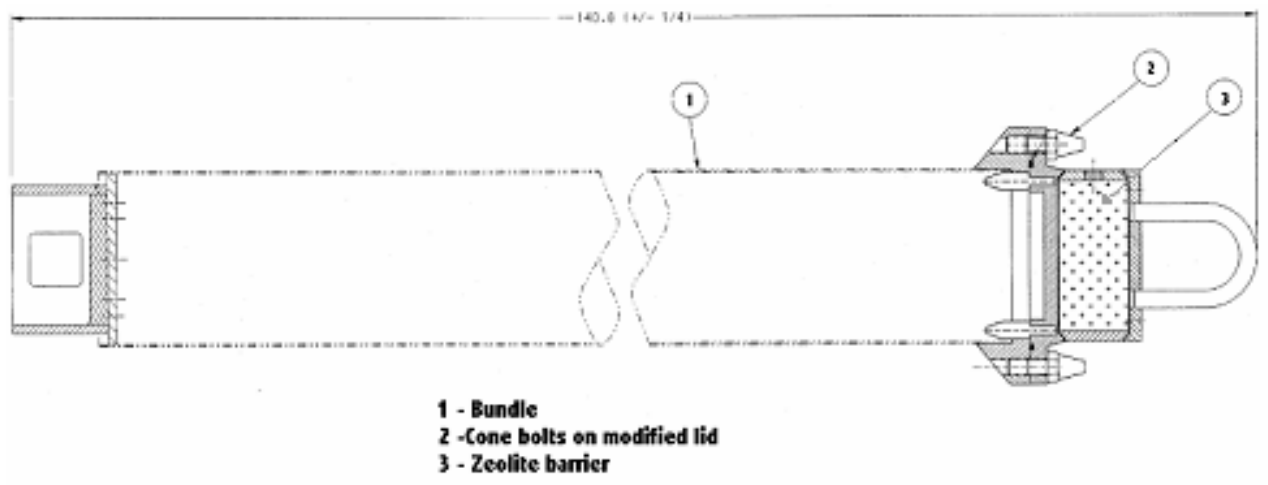

Figure 3. Zeolite-capped bundle. 


\subsection{MARK 0, II, AND II FUEL STORAGE CANISTER}

For underwater storage of zircaloy clad, uranium metal fuel at the Hanford Site, canister designs evolved from those originally intended to support transfer and feed of fuel to reprocessing systems. Each canister had two barrels that held up to seven elements vertically. Mark 0 canisters (see Figure 4) had screen bottoms and open tops and were fabricated from aluminum. These canisters were not intended for extended fuel storage and did not adequately confine fuel and fuel-water reaction products from the storage environment. Later designs (Mark I and Mark II canisters) (see Figure 5) had solid bottoms and sealable tops. Each sealed canister barrel was vented through an external gas trap to prevent any buildup of pressure within the canister. The Mark I canisters were made of either aluminum or stainless steel. The Mark I lid seal used a Grafoil gasket that could inadvertently fall into the canister during lid removal and be introduced into the fuel reprocessing systems, causing potential pluggage of process equipment. The Mark II canisters (see Figure 6) were the final generation of underwater storage canisters, were fabricated from stainless steel to eliminate corrosion issues experienced with aluminum canisters, and included an improved lid seal design.

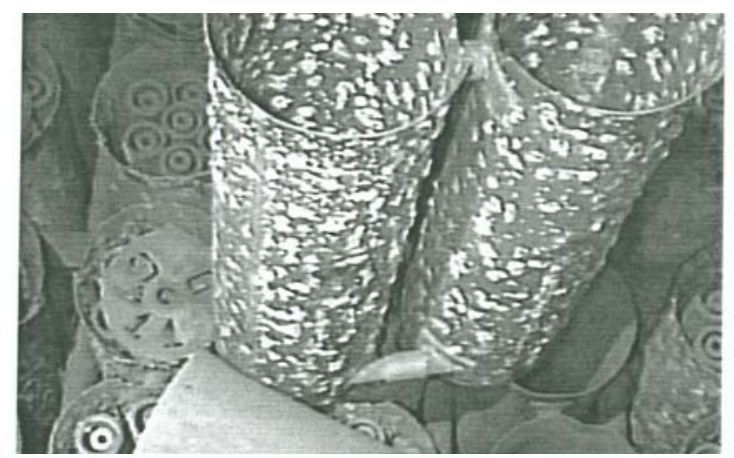

Figure 4. Mark 0 aluminum canister.

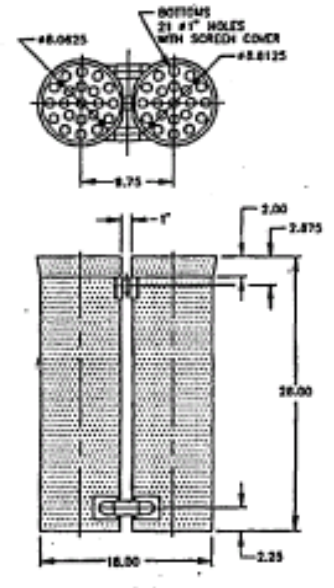

MARK $O$ CANISTERS .
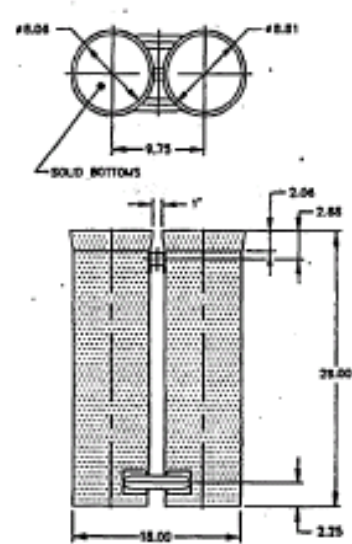

MARK I CANISTERS
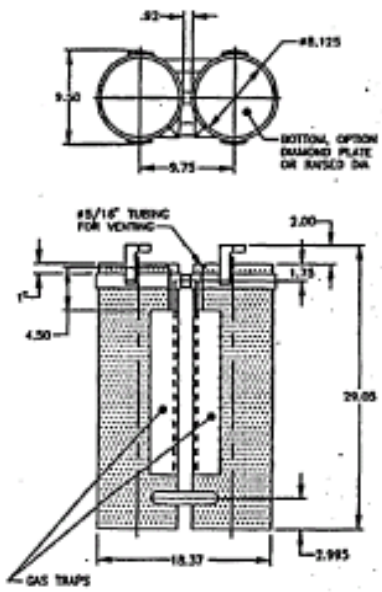

MARK II CANISTERS

Figure 5. Mark 0, I, and II canisters. 


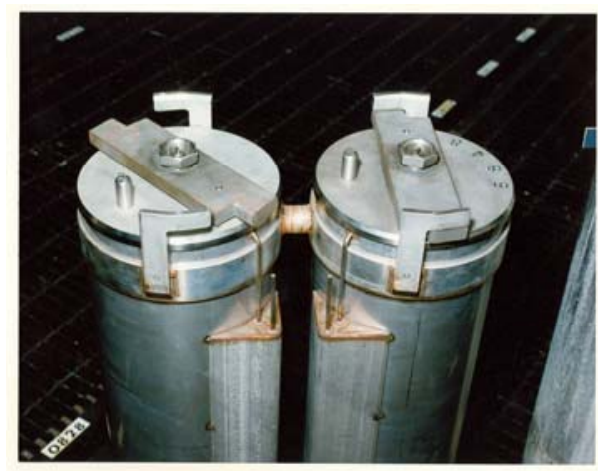

Figure 6. Mark II stainless steel canister.

All three types of canisters were filled under water. The fuel, water, and gas volumes in the canisters varied with the type and condition of the fuel. When the Mark I and Mark II canisters were originally filled with fuel and closed, the top $2.5 \mathrm{in}$. of water in each barrel were displaced with inert nitrogen gas. In some instances, the canister lid locking bar (martensitic type 416 stainless steel, heat treated to a high stress level) was observed to be broken or cracked, creating concern over loss of the nitrogen gas from the canister. This was believed to have been caused from hydrogen-induced cracking. Hydrogen generated in the canister during storage could also displace nitrogen from the canister. The closed lids also enabled use of potassium nitrite, an oxygen scavenger, to inhibit corrosion during storage. The potassium nitrite was added prior to sealing of the canisters. The lidded Mark I and Mark II canister designs combined with basin water control systems did effectively control contamination levels within the storage basin.

\subsection{Rod Consolidation Assembly}

Fuel pins were removed from commercial origin Boiling Water Reactor and Pressurized Water Reactor spent fuel assemblies for various examinations in support of repository performance assessment testing. A rod consolidation assembly was designed to enable handling and ensure geometry control for criticality safety during subsequent handling and storage of the fuel pins (see Figure 7). The assembly design used a standard commercial fuel lifting fixture to enable handling at a fuel handling facility without unique tools. The bottom of the assembly includes a perforated plate to enable helium contact with the fuel rods for vacuum drying and inerting, while maintaining particulate confinement for any potentially damaged fuel.

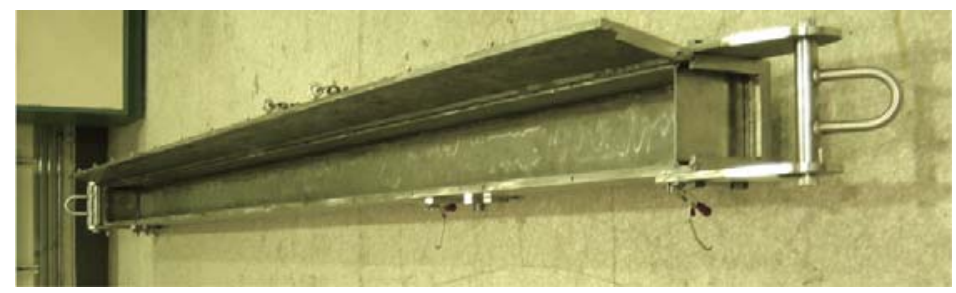

Figure 7. Rod consolidation assembly (shown with temporary lifting fixture). 


\section{LID CLOSURE DESIGNS}

Several lid designs have been used for the SNF canisters. The designs incorporate specific features to facilitate underwater opening and closure operations. These features include keepered lid bolts, special conical shaped bolts, and lid alignment pins.

Bolted lids have the advantage of easy installation and removal. In many cases, other style lids (welded, screw top and tabbed), while easily installed, do not incorporate an easy method of opening the can. The disadvantage to bolted lids is that they usually require a flange that reduces the canister opening or increases the storage cell size relative to the size SNF that can be placed in the canister.

\subsection{Keepered Lid Bolt}

The keepered lid bolt is a bolt that is retained in the canister lid via a partially threaded bolt hole. This feature allows for easy installation of the lid with no need to handle small loose bolts in remote situations. Typically, the bolt hole is tapped slightly less than the thread length on the bolt. The remainder of the hole is unthreaded. The bolt for the lid is only threaded on the bottom section, with the threads removed from the upper portion (typically equal to the thickness of the lid flange material). Failure to properly design the lid bolt holes can cause cross-threading during installation.

Figure 8 is a cross section of a typical keepered lid bolt arrangement.

\subsection{Lid Bolt Strength}

Lid bolts are designed with criticality accident scenarios in mind. In most cases, the lid will be significant to containing the material and maintaining geometry control of the damaged SNF in or near an array of other SNF. The frequency or potential for incorrect installation of the lid is mitigated by making one bolt capable of sustaining the entire load imposed during handling. This reduces the frequency of failure as there is a preengineered solution to improper fastening of lid bolts during installation.

\subsection{Cone Shape Bolts}

Design of fastener heads incorporates a conical shape above the standard hex head (Figure 8). This allows for easier remote engagement of the socket/tool on the bolt.

\subsection{Lid Alignment Pins}

Lid designs incorporate alignment pins, which allow for proper alignment of lid on the storage canister. The keepered lid bolt, alignment pins, and cone-shaped bolts were used on the zeolite-capped bundle (Section 1.2) as shown in Figure 9. In this case, the alignment pins do not fit into the traditional holes, but instead use the canister opening shape to guide the pins. This allows for a larger canister opening. 

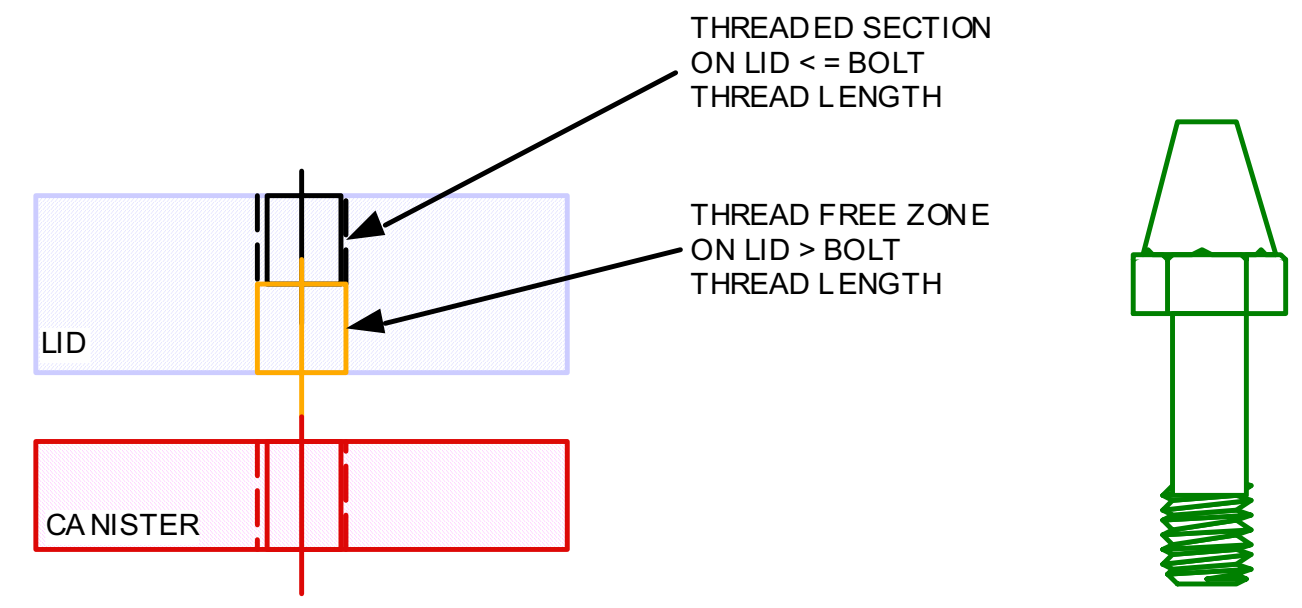

Figure 8. Typical keepered lid bolt layout.

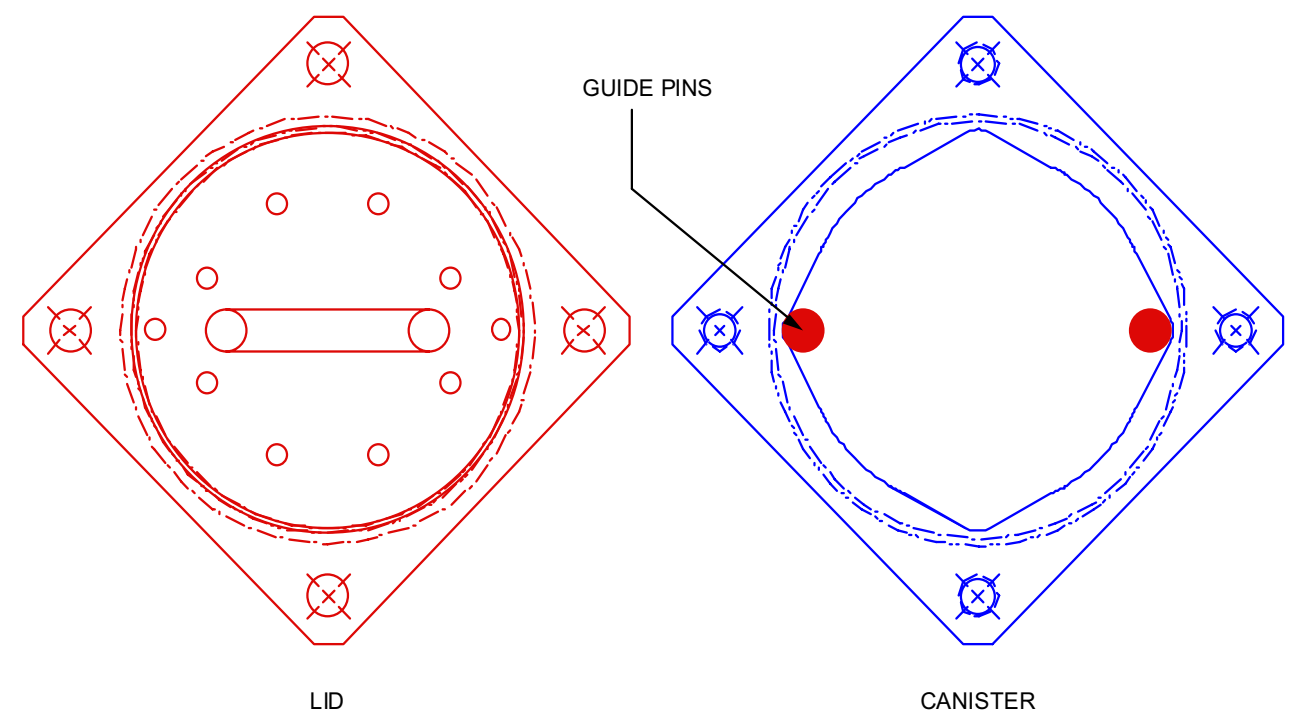

Figure 9. Keepered lid bolt and cone bolt detail for zeolite capped bundle.

\subsection{Tabbed Lid Closures}

Tabbed lids are used where space is critical and a bolted lid attachment is not feasible. Tabbed lids use a load bar to sustain the loads imposed during handling; the tab merely maintains the orientation of the lid such that the load bar is properly positioned. Tabs have been used in several bundle designs from a canister type design to an open suitcase-type design (Figure 10).

The benefits of the tabbed lid closure are easy installation and verification of proper installation. During installation, the tabs are simply bent into position using a handling tool and verified by visual 
inspection (utilizing underwater camera, binoculars, or by eye). This design utilizes less material, which is advantageous when the material's ultimate disposition is to be dissolved, such as during reprocessing. Additionally, design of a tabbed lid closure is simpler than that of a bolt type closure. This feature is most effective when the amount of tabbing (degree of bend) is not a critical design feature.

The drawbacks to the tabbed lid closure involve the difficulty in opening a tabbed canister. This requires cutting the canister open, which introduces an accident scenario of cutting thru SNF. There is also a potential for breaking a tab off during lid installation, which requires repackaging the fuel and disposing of the damaged canister.

\subsection{Other Lid Closure Designs}

There are several alternative lid designs that use concepts from both the tabbed and bolted design features described. One design uses a cam lock style lid that has four posts (see Figure 11), which engage in precut openings of the canister. This style lid is maintained closed by engaging a single bolt in the corner of the canister/lid, which prevents the lid from rotating. Another style lid uses the bundle and lid shown in Figure 10. The lid is modified by removal of the tabs and installation of a block, which contains an internal bolt. The lid is installed in the same manner as the tabbed lid, with the bolt performing the function of the tab when backed out (Figure 12).
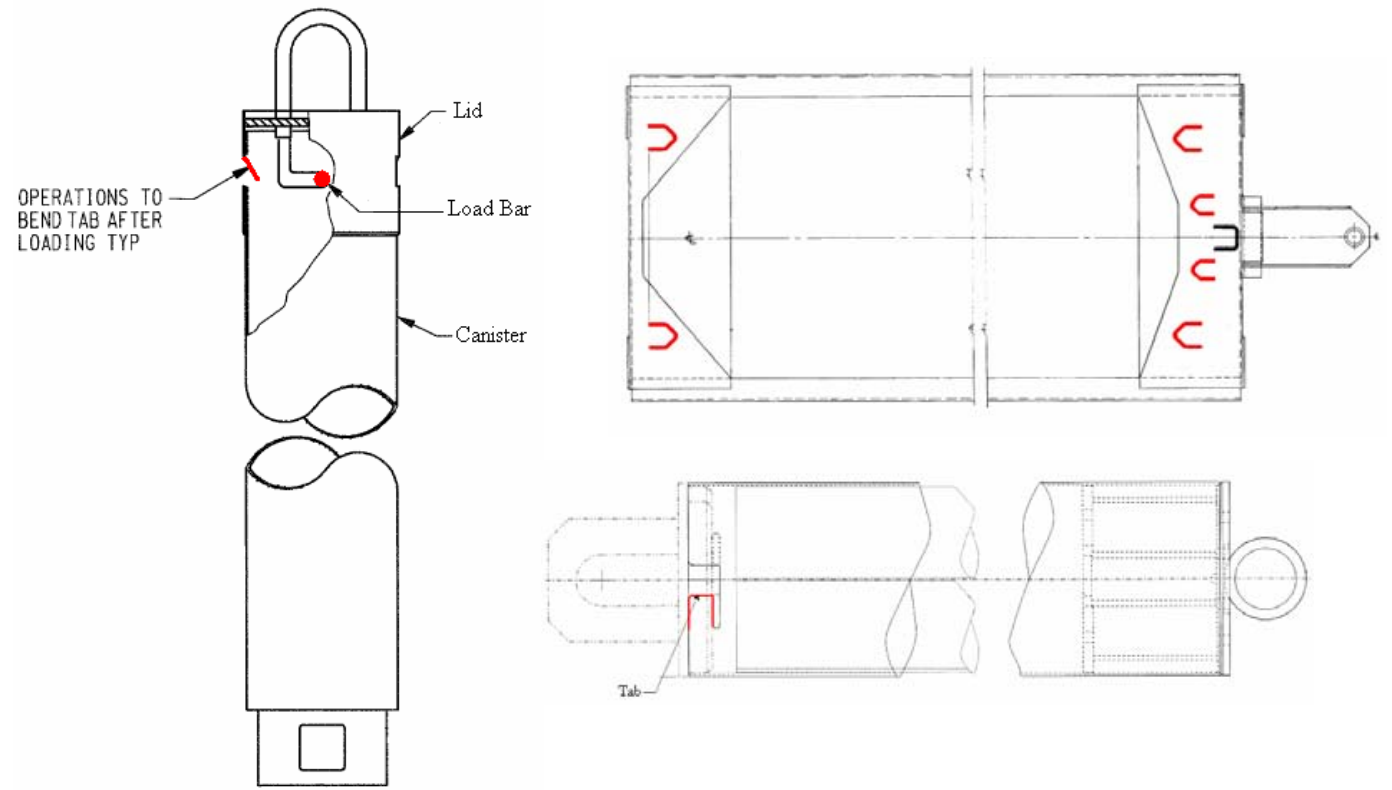

Figure 10. Tabbed closure examples: EBS-Bundle (left), Savannah River Site Fuel Bundle (top right), inner canister (bottom right). 

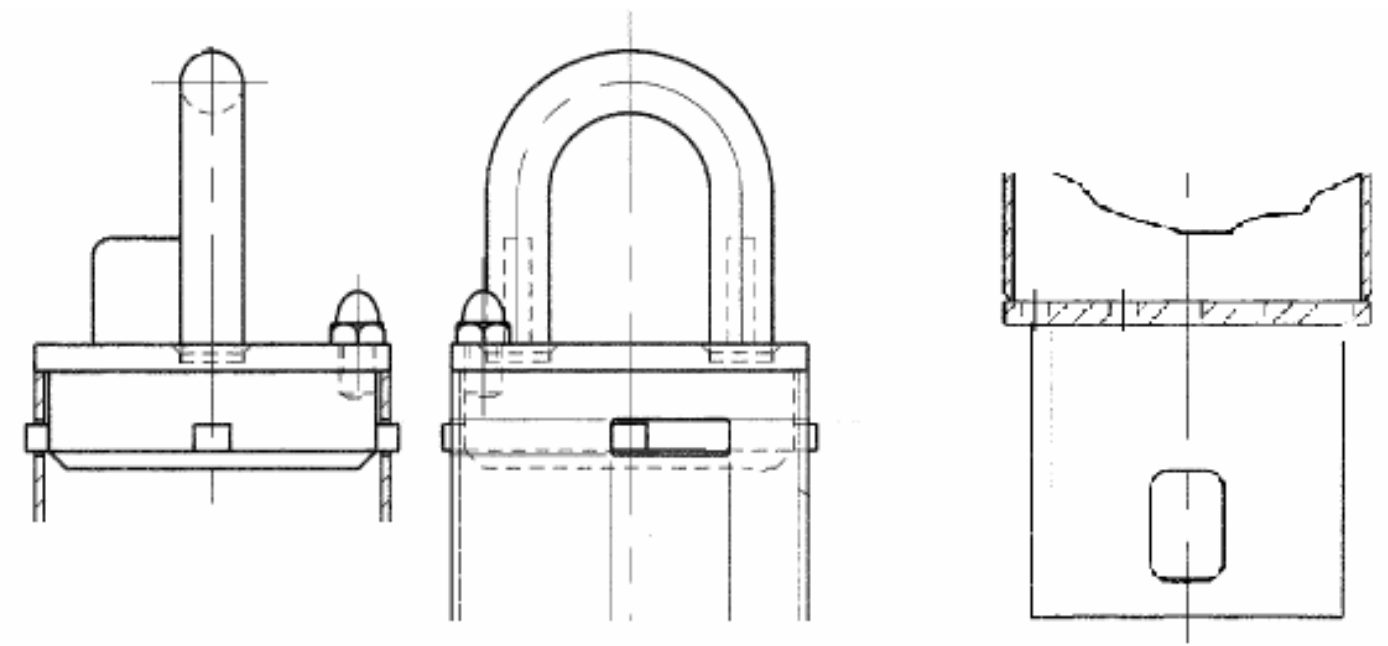

Figure 11. Typical lid lifting bail (left) and rigging point on bottom of bundle (right).
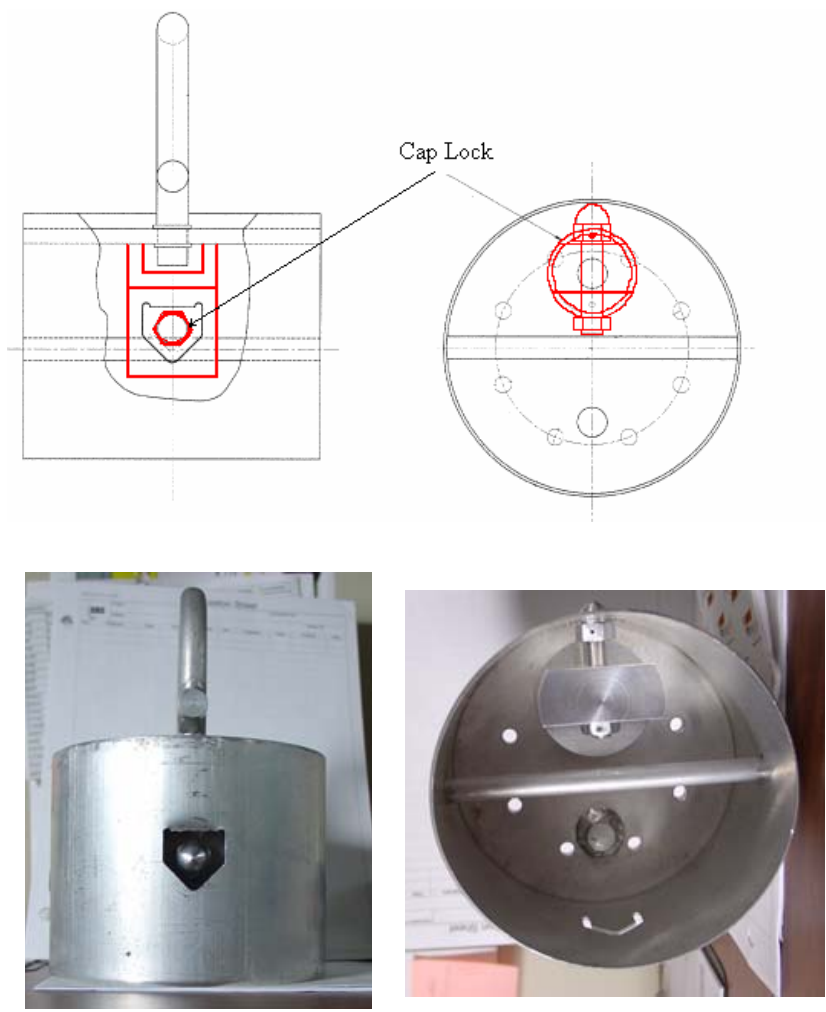

Figure 12. Alternate lid style. 
The advantages of these style lids are the combination of the ease of installation of the tabbed style lid and the ease of removal of the bolt style lid. The disadvantage to this style lid is the tight

manufacturing tolerances required to ensure the lid does not rotate enough to disengage from the canister.

\section{OTHER DESIGN CONSIDERATIONS}

\subsection{Bail or Handling Fixtures}

In many cases the lifting fixture of the container has been attached to the container's lid. This is not typically a problem for empty light-weight canisters. However, a drawback to this design is that manipulation without the lid is difficult. Further, for heavy containers, it can be difficult to lift the containers from the lid, and lifting fixtures on the canister body should then be considered. This issue becomes evident when removing damaged SNF from a previously loaded canister. A typical lifting bail is shown in Figure 11.

Often when designing a container's lifting fixture, little consideration is given to the next evolution for the fuel package. As a specific example, pivoting lifting bails (see Figure 13, Container A) are convenient in a water storage environment, but a lifting bail may be difficult to engage with a remote tool in a dry cell. If a lifting bail must be used, it is good to design the bail such that when it falls to a horizontal orientation, a gap remains between the lid and the bail sufficient for a tool to slide under the bail. In the design illustrated by Container A in Figure 13, the lifting bail rests on the bolt head leaving room for a tool.

Lifting fixture designs that accommodate both environments can be devised. Container B in Figure 13 shows a 12-cm-diameter container that is designed to allow handling with three methods. The can, with the lid secured in the J-slots, can be lifted from the metal tab on the lid with simple underwater tools. Or it can easily be engaged remotely with a tool that drops over the tab and then latched in the slot. The container can also be handled without the lid affixed by lifting it from the square slots or the J-slots at the top of the can.

The lid for Container B is affixed to the container as shown in Figure 14. The lid is fabricated with the round bar of the lifting fixture being threaded, as is the triangular lid piece. After the triangular lid piece is threaded onto the rod, the circular lid piece is welded to the bottom of the rod. The lid is secured to the can by placing the three tabs into bottom of the J-slots and rotating the lifting fixture clockwise. The rotation causes the triangular lid piece to move up until it is fully engaged in the J-slots.

Design of lifting points on canisters should also take into consideration the possible need to rotate the container from vertical to horizontal, consideration of overall container weight, and the different loads imposed on the bail or handling fixture. 


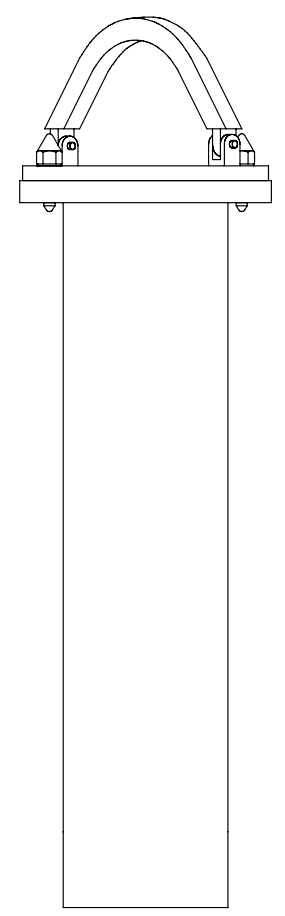

Container A
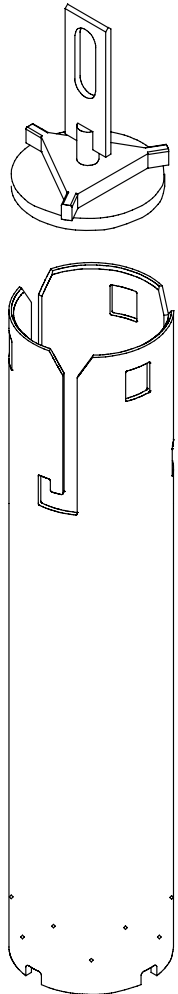

Container B

Figure 13. Two additional container lifting fixture designs.

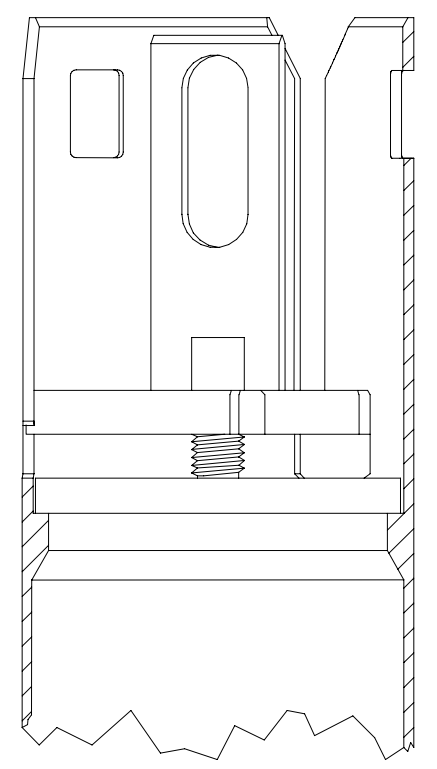

Figure 14. Lid engagement. 


\subsection{Canister Identification}

The combination of SNF assembly damage and emplacement in a canister renders the unique assembly identification useless. Unique identification is typically applied to the canister for traceability and accountability. Typically canister identification has been accomplished by using indelible ink markers. This method has been shown to work for a reasonably long period of time. However, because of the unexpected extended storage times, facilities are finding that the ink fades or wears off. This is even true for items rarely handled and markings in areas that do not ever experience contact with other surfaces. A recent practice has been developed, which involves engraving the bundle/canister lids to provide for long-term identification. In order to address the previously stored bundles, tags with engraved identifications have been designed and are being installed. Although the engraved identification numbers are readable underwater, they are filled in with low chloride indelible ink for better visibility (see Figure 15). Notice that the design of the tag allows for easy installation over the bail, but an angled tab prevents the tag from falling off even when the bundle is handled horizontally.

\subsection{Fuel Free Zone}

The fuel free zone is a region preengineered into the bundle design that is a known safe location to cut the canister. Cutting the canister open is necessary when it does not have a bolted/screwed lid or the bolted/screw lid is not functioning properly. This feature is especially important when dealing with damaged fuel, which results in smaller pieces and parts whose location inside a canister may be hard to anticipate. Many new canister designs have incorporated a fuel free zone design feature that ensures a safe location to cut the canister and gain access to the fuel. An example of the fuel free zone is the bottom region of the inner canister, shown in Figure 16. This feature can also be used to provide criticality spacing where required.

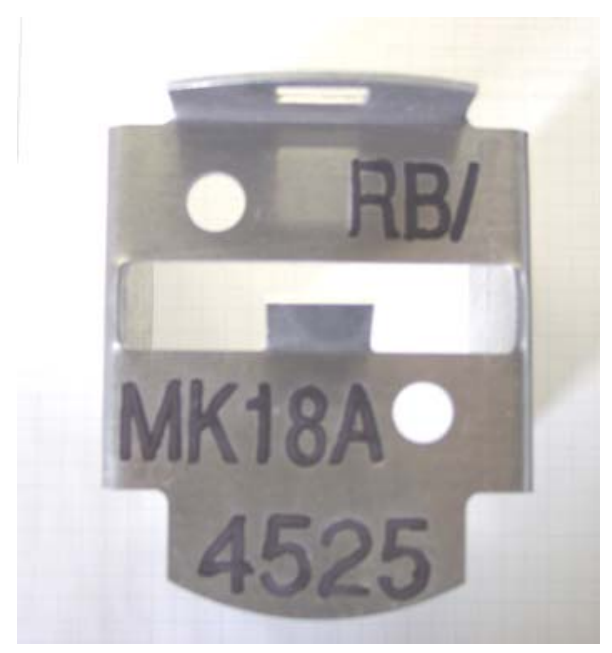

Figure 15. Etched and filled in identification tag. 


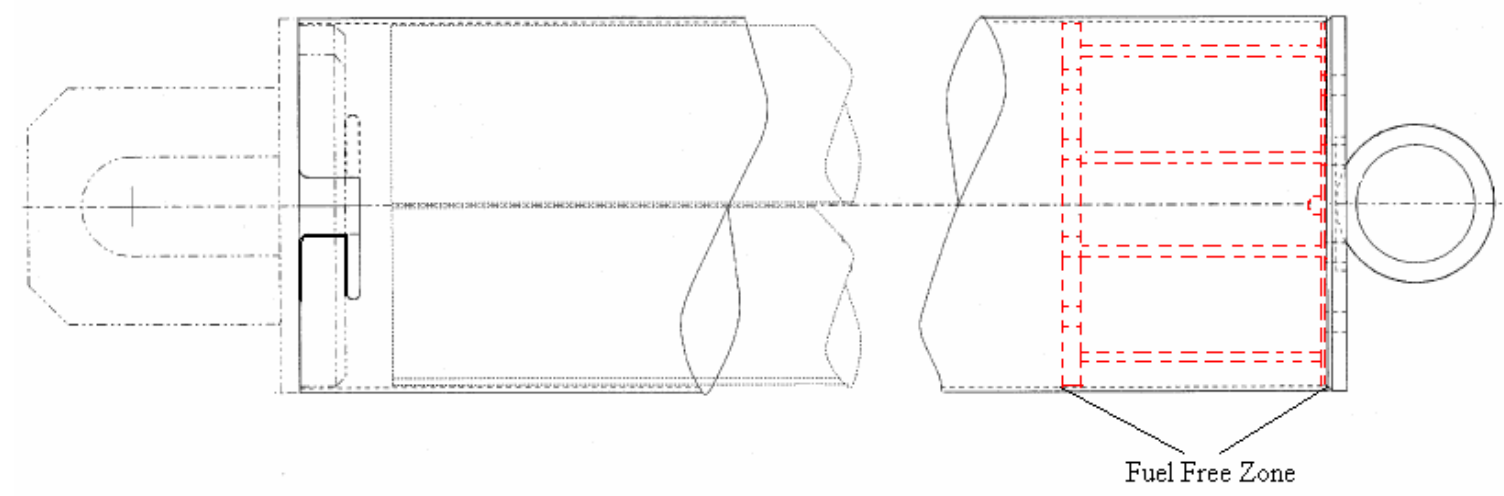

Figure 16. Inner canister fuel free zone.

\subsection{Flushing/Sampling Connections}

Flushing/sampling connections are provided on canisters that act as a containment boundary between SNF and the storage pool water. These connections provide a means for sampling the internal water environment and flushing prior to opening. This allows for better characterization of the hazards involved with opening the canister and a more controlled release of the activity into the storage pool. Flushing the canister prior to opening has the added advantage of reducing waste volume as a portable filtration/deionization system can be used, minimizing the impacts on the storage pools system.

\subsection{Drop Analysis}

The primary function of the canister is to maintain the geometry of the SNF consistent with the criticality analysis. This includes credible drop accidents and handling events. Simple impact limiters and crush zones have been used to absorb the energy of a canister drop without negatively impacting the contained SNF or releasing the contents (See Figure 17).

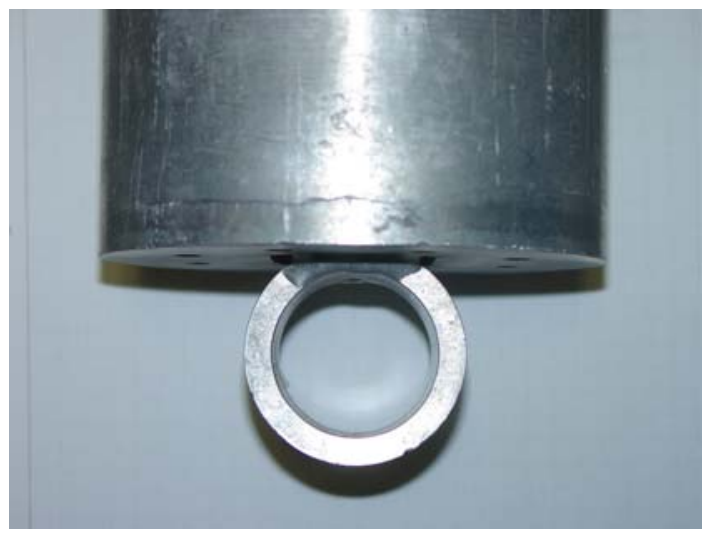

Figure 17. Simple impact limiter.

\subsection{Thermodynamic Design Considerations}

The design of the storage canister needs to consider the potential heat buildup and ensure the SNF is not negatively affected, which could result in a variance from the criticality analysis. Typically, this is 
accomplished by designing canisters such that water flows through the bundle or storage rack via convection.

\subsection{Canister Materials}

Storage canister materials should be chosen to minimize corrosion of SNF cladding. For sealed canisters with an inert atmosphere, the canister material will not impact the SNF cladding corrosion. In unsealed canisters or sealed canisters with a moist atmosphere, the canister and SNF cladding materials should be similar. If the canister and SNF cladding materials are different, galvanic couples are created. The SNF cladding metal should be the less reactive metal (cathode) in the galvanic couple. Aluminum is a more reactive metal than stainless steel or zirconium. Stainless steel or zirconium clad SNFs can be stored in aluminum canisters, but aluminum clad SNFs should not be stored in stainless steel canisters. Another driving force in a galvanic couple is a large cathode to anode ratio. Stainless steel canisters are acceptable in aluminum racks, but aluminum canisters should not be stored in stainless steel racks.

Another consideration for canister materials is the final end state of the SNF. The canister materials should be compatible with the transportation and final disposition requirements for the SNF. For example, SNF that is destined for a dissolution process should be canned in material compatible with that process.

Uranium and uranium/zirconium metal SNFs should be stored in canisters allowing for expansion of $\mathrm{UO}_{2}$ corrosion product. The $\mathrm{UO}_{2}$ density is about $50 \%$ of the uranium metal density, so the uranium corrosion product will occupy about twice the volume of the original uranium SNF. If the SNF is tightly packed, the canister might burst. This has occurred within the DOE complex.

\subsection{In-Canister Criticality of Degraded SNF}

In-canister criticality of degraded SNF is an accident scenario where the SNF degrades into a more reactive configuration. Canister design should incorporate features to maintain configuration if degraded SNF is subject to criticality concerns. Examples of this would be compartmentalized canister inserts or placement of smaller canisters within a larger canister, thereby maintaining the analyzed configuration of the SNF. Maintaining a critically safe geometry is a consideration any where damaged or degraded SNF may accumulate (e.g., beneath storage racks). 